\title{
Damage identification of brick masonry under cyclic loading based on acoustic emissions
}

\author{
Haris Alexakis ${ }^{a, b, *}$, Han Liuc ${ }^{c}$ Matthew J. DeJong ${ }^{d}$
}

\begin{abstract}
${ }^{a}$ Visiting Academic Fellow, Centre for Smart Infrastructure and Construction, University of Cambridge, Civil Engineering Building, JJ Thomson Avenue 7a, CB3 OFA Cambridge, United Kingdom

${ }^{\mathrm{b}}$ Lecturer in Civil Engineering, School of Engineering and Applied Science, Aston University, B4 7ET

Birmingham, United Kingdom
\end{abstract}

* Corresponding author, E-mail: ca510@cam.ac.uk \& c.alexakis@aston.ac.uk

ORCID: https://orcid.org/0000-0002-6588-2070

c PhD Student, Department of Civil and Environmental Engineering, University of California, Berkeley, United States

\author{
${ }^{\mathrm{d}}$ Assistant Professor, Department of Civil and Environmental Engineering, University of California, \\ Berkeley, United States \\ ORCID: https://orcid.org/0000-0002-6195-839X
}

\begin{abstract}
:
Ageing infrastructure, such as masonry railway bridges, suffers from structural deterioration due to fatigue loading. This paper presents an experimental study of brick masonry deterioration under gradually increasing cyclic loading with the aid of Acoustic Emission (AE) sensors. Two masonry beams were tested in the laboratory under similar stress conditions that masonry arches experience during train loading. An in-house AE monitoring system was developed for this study allowing both featurebased and waveform-based AE analysis. In the lab tests, different modes of damage were activated, such as tensile bond failure, brick and mortar crushing, diagonal shear failure and joint sliding. Featurebased $\mathrm{AE}$ analysis shows an increase in cracking rate before brittle failure events that is not necessarily accompanied by an increase in deformation rate. Statistical analysis reveals clear trends in AE results that correlate to different damage stages. The paper discusses how these findings can be leveraged to develop real-time structural alert systems that could provide early warning of damage before a significant increase in dynamic deformation occurs.
\end{abstract}

Keywords:

acoustic emission; railway bridge; smart infrastructure; structural health monitoring; asset management; non-destructive testing 


\section{Introduction}

Rail infrastructure deteriorates with time due to many factors, including material fatigue, overloading, ground movement and environmental effects. At the same time, traditional inspection practices and fragmented monitoring can be inadequate to ensure adequate maintenance on a national scale. Digitisation of infrastructure networks emerges today as an essential next step to address this challenge for secure and resilient societies. Enhancing our understanding of the structural deterioration mechanisms is an indispensable part of this process in order to develop decision making tools for the maintenance of infrastructure networks.

Ageing masonry bridges comprise around $50-60 \%$ of the UK and European rail stock $[1,2]$ and their structural assessment is particularly challenging. The majority of these structures were built more than a century ago, before the enforcement of building codes. Masonry is a non-uniform, composite material, with low tensile strength and an inherently discontinuous nature, which makes structural modelling challenging. At the same time, due to the absence of monitoring data, there is usually a lack of information on the deformation and loading history of the structure.

In the UK, the overall structural performance of masonry railway bridges is commonly assessed by measuring the vertical deflection of arches at various locations (most commonly at the keystone) with the use of displacement gauges mounted on poles [3]. However, the deflection pole technique requires access underneath the arches that might require road closures, and is impractical where bridges cross tall valleys or rivers. In addition, local behaviour of cracks is typically monitored with cement tell-tales. Deflection pole and tell-tale monitoring are well established techniques, which nevertheless demand time consuming site inspections and are not suitable for continuous monitoring of a large number of bridges. Furthermore, these monitoring data offer limited insight into the complex deterioration mechanisms involved.
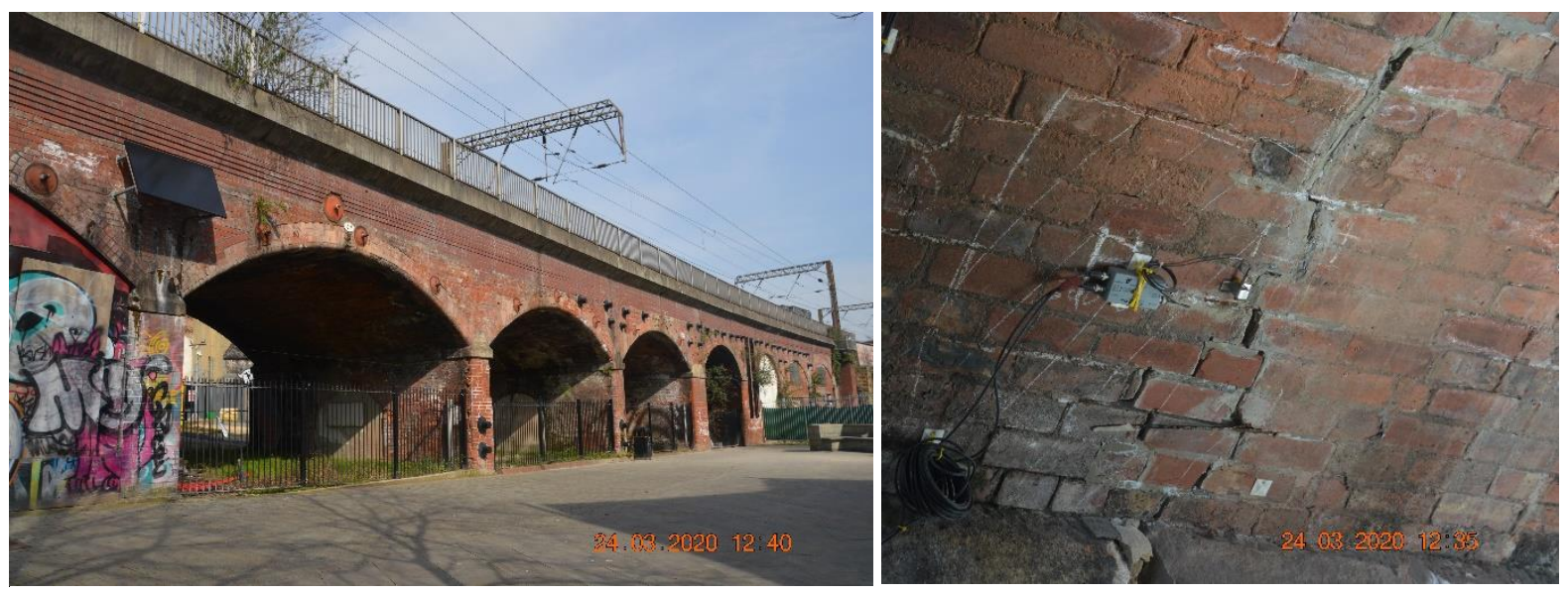

Fig. 1. Left - The Marsh Lane Viaduct, Leeds, UK. Right - An AE sensor monitors a bending crack that propagates in the arch barrel.

In an effort to address these challenges, Alexakis et al. [4] developed a multi-sensing system to monitor degradation of masonry railway bridges. The system monitors distributed dynamic strain with a network of fibre Bragg grating sensors, material damage with acoustic emission (AE) sensors and bridge dynamic response with low noise accelerometers. The motivation for this work was the need to assess the long-term structural performance of the Marsh Lane Railway Bridge, shown in Fig. 1-left, which is a Victorian brick masonry viaduct in the UK, located near the East entrance of Leeds Railway Station. Statistical analysis of fibre Bragg grating strain and temperature data over a period of two years after the repair, 2016-2018, combined with a train classification algorithm, showed high sensitivity in detection of dynamic strain changes due to cyclic temperature variations and material degradation $[5,6]$. 
AE sensors were then installed in 2018 to evaluate the rate of damage at critical locations. For instance, Fig.1-right shows one of these locations monitored by an AE sensor, where a bending crack propagates in the arch barrel. Bending and shear cracks of varying width due to mixed in-plane and out-of-plane dynamic response mechanisms of the piers and arch barrels are extensive in the bridge. The reader is referred to previous works of the authors for a detailed description of the bridge damage [4-6].

Apart from monitoring changes in the cracking rate of severely damaged areas, like the one in Fig.1right, $\mathrm{AE}$ sensors also provide the potential for early detection of progressive material damage due to, for example, gradually increasing cyclic train loading, before the damage manifests itself in observable increases in dynamic displacement. However, as will be discussed in the next section, there is limited literature that describes the bending and shear behaviour of brick masonry based on AE under cycling loading.

In an effort to correlate long term AE monitoring data with the current structural state and deterioration rate, this paper presents an experimental study for the structural assessment of brick masonry with the aid of $A E$ sensors. An in-house $A E$ sensing system was developed for this experimental study, similar to the one installed in the Marsh Lane Bridge, allowing direct comparison with field monitoring data. The paper presents results from two unreinforced brick masonry beams subjected to horizontal compressive force and gradually increasing cycling bending loading until collapse. The loading combination of axial compression in addition to shear and bending was selected to be a similar loading condition to what a section of an arch bridge barrel might experience due to both self-weight and train loading.

During the tests, different modes of damage were activated, including bond failure, brick and mortar crushing, diagonal shear failure and joint sliding. The paper presents the evolution of AE signal features at different damage levels and results from a statistical approach, the $b$-value analysis, which is based on the magnitude distribution of $A E$ events. The study evaluates the behaviour of masonry at different performance states that are associated with micro-cracking (low damage state) and extensive microand macro-cracking (high damage state) and identifies intermediate (transition) states associated with temporary increases of macro-cracking events. Based on the results, the paper discusses the use of AE sensors to develop early warning structural alert systems and to evaluate the life cycle structural performance of masonry infrastructure.

\section{Infrastructure monitoring with Acoustic Emission (AE) sensors}

Acoustic emission (AE) is the phenomenon where transient elastic waves are generated by rapid release of energy from localised sources within the material [7]. Typically these sources are sudden irreversible changes in the internal structure of the material such as cracking [8]. AE sensors are piezoelectric sensors used to detect elastic waves, which have small amplitude (in the order of $\mathrm{nm}$ ) and high frequency (in the order of $10 \mathrm{kHz}$ to over $1 \mathrm{MHz}$ ), requiring data acquisition systems with high sampling rates.

$A E$ is a passive non-destructive testing method, suitable for continuous infrastructure monitoring. $A E$ sensors have been widely used in the field of SHM for leakage detection in high-pressure containers and pipelines [9] and damage detection in steel and concrete structures [10]. AE monitoring is also used to study the behaviour of rock [11] and soil [12].

For concrete bridges, industry applications are mainly limited to detection of wire breaking in suspension/cable stay and post-tensioned concrete bridges. A wire breaking radiates a high energy acoustic wave, which results in a distinguishable signal. Cables are one-dimension structures with low signal attenuation, which facilitates the detection and localisation of damage with the use of simple 
algorithms. However, recent advances in data acquisition and data processing have shown that this is a small fraction of potential AE applications, which may also include damage severity assessment, three-dimensional source location and source discrimination [10].

The directness of AE for wire break detection made it a popular SHM approach for suspension bridges and pre-stressed concrete bridges, whereas, field applications for masonry bridges have been limited $[6,13,14,15]$. Reasons for limited use include high signal attenuation in masonry and the heterogeneity of the material, which can make damage localisation challenging [16, 17].

Masonry railway bridges suffer from fatigue. Fatigue deterioration of masonry has been studied experimentally with small-scale specimens under compressive or diagonal (shear) cyclic loading [15, $18,19]$. Before these experimental studies that use a uniaxial load approach, Melbourne and Tomor [20] researched multi-ring arches under point cyclic loading. While this experimental work was the first to monitor acoustic emissions in masonry subjected to combined bending and shear, the absence of superstructure or backfill and the low arch thrust resulted in early formation of hinging and ring separation collapse mechanisms. As a result, the progressive AE behaviour of masonry under biaxial stress state could not be measured. The current paper studies the AE behaviour of masonry specimens under progressive damage due to biaxial loading, including the combined effect of compression, shear and bending that arch sections experience during train loading.

\section{Experimental setup}

\subsection{Materials and specimens}

This study presents the AE behaviour of two brick masonry specimens under gradually increasing cyclic loading. Fig. 2 shows one of the specimens on the test rig before testing. Fig. 3 is a schematic representation of the test setup. The length of the specimen in the longitudinal direction is $1110 \mathrm{~mm}$. The height and the width of the specimen coincide with the length and the width of the bricks, which are $215 \mathrm{~mm}$ and $102.5 \mathrm{~mm}$ respectively. The thickness of the bricks is $65 \mathrm{~mm}$ and the thickness of the joints is approximately $7.5 \mathrm{~mm}$. A cut-off saw was used to reduce the thickness of two bricks at $1 / 4$ of the span, so the specimen could fit in the load frame with the central joint directly below the applied vertical load. Initial cracking was expected at the central joint, which was selected for detailed AE monitoring. The 16 bricks are numbered from left to right as shown in Fig. 3 below the specimen.

Masonry railway bridges in the UK are typically built of solid clay bricks. Solid clay bricks were selected in this study with a gross dry density of $2310 \mathrm{~kg} / \mathrm{m}^{3}$. The bricks are classified according to BS EN 771-1 European Standards for clay masonry units as "Engineering B", with minimum compressive strength $75 \mathrm{MPa}$ and maximum water absorption 7\%. For the two specimens presented in this study, a ready mixed sand cement mortar of category M5 was used, with a minimum compressive strength $5 \mathrm{MPa}$ at 28 days, according to BS EN 998-2:2010. A 10mm-thick layer of mortar at the bottom of the specimen was required to align the bricks during the preparation of the specimen. The specimens were left to mature for 28 days.

Although commercially available bricks and mortar were used in this study, which resulted in masonry specimens of higher strength compared to historic masonry of ageing infrastructure, this paper aims to identify general patterns in the acoustic emission behaviour of masonry under progressive damage due to train loading. Conducting a parametric experimental investigation to compare the acoustic emission behaviour of masonry with varying mechanical parameters is of interest for future research.

\subsection{Test set-up}

The tests were performed at the Structures Laboratory of the Department of Engineering, University of Cambridge, UK. The load frame is shown in Fig. 2. A servo hydraulic actuator was fixed at the centre 
of the frame. The vertical displacement was measured with a laser transducer mounted on the actuator, whereas the applied load was measured with a $100 \mathrm{kN}$ load cell at the bottom end of the actuator. The vertical load was applied to the specimen through steel roller bearings, shown in Fig. 3, to equalise the load between the two central bricks. Steel roller bearings were also used as endsupports of the masonry specimen.

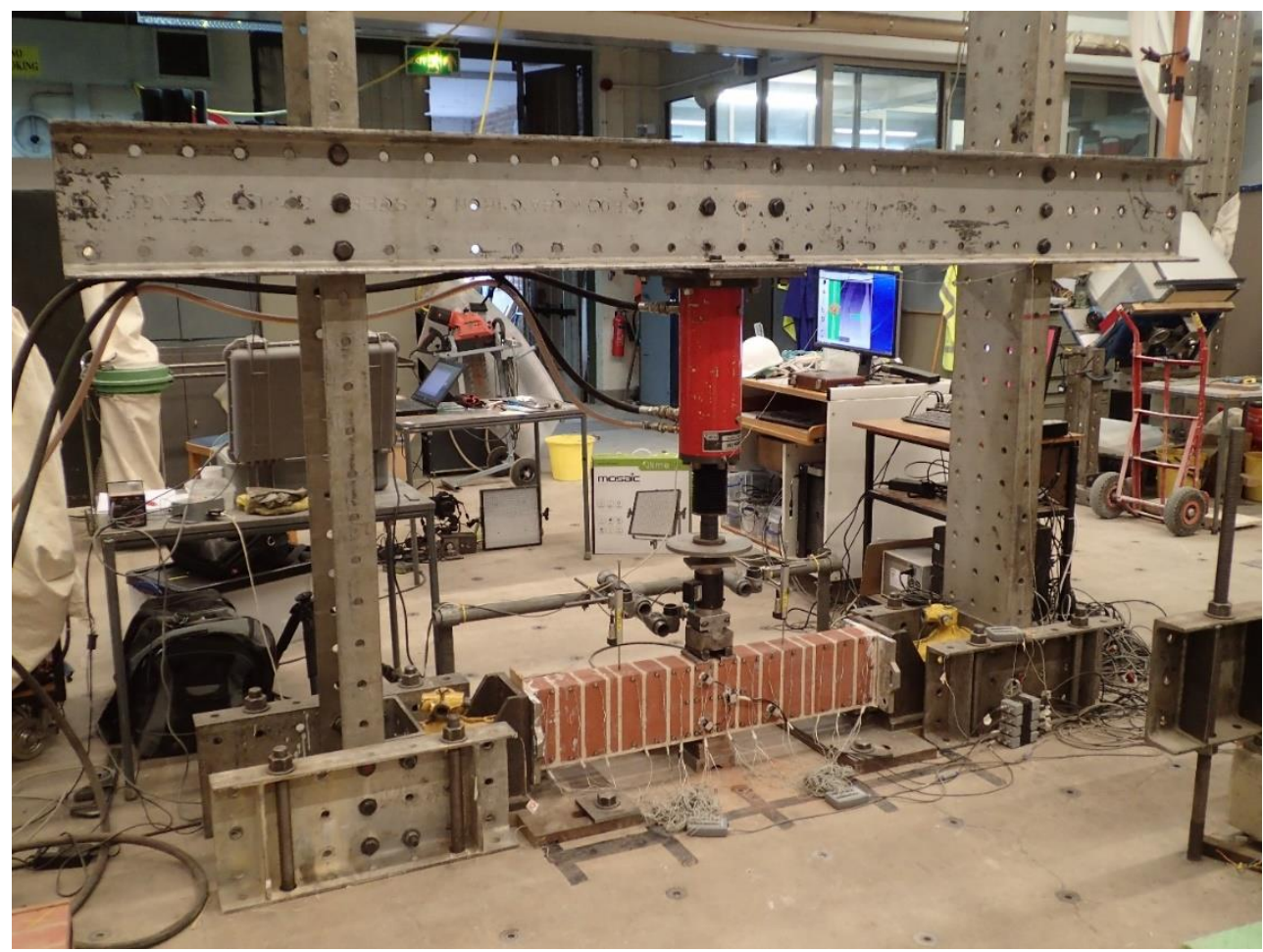

Fig. 2. Test set-up for gradually increasing cyclic load on masonry specimens.

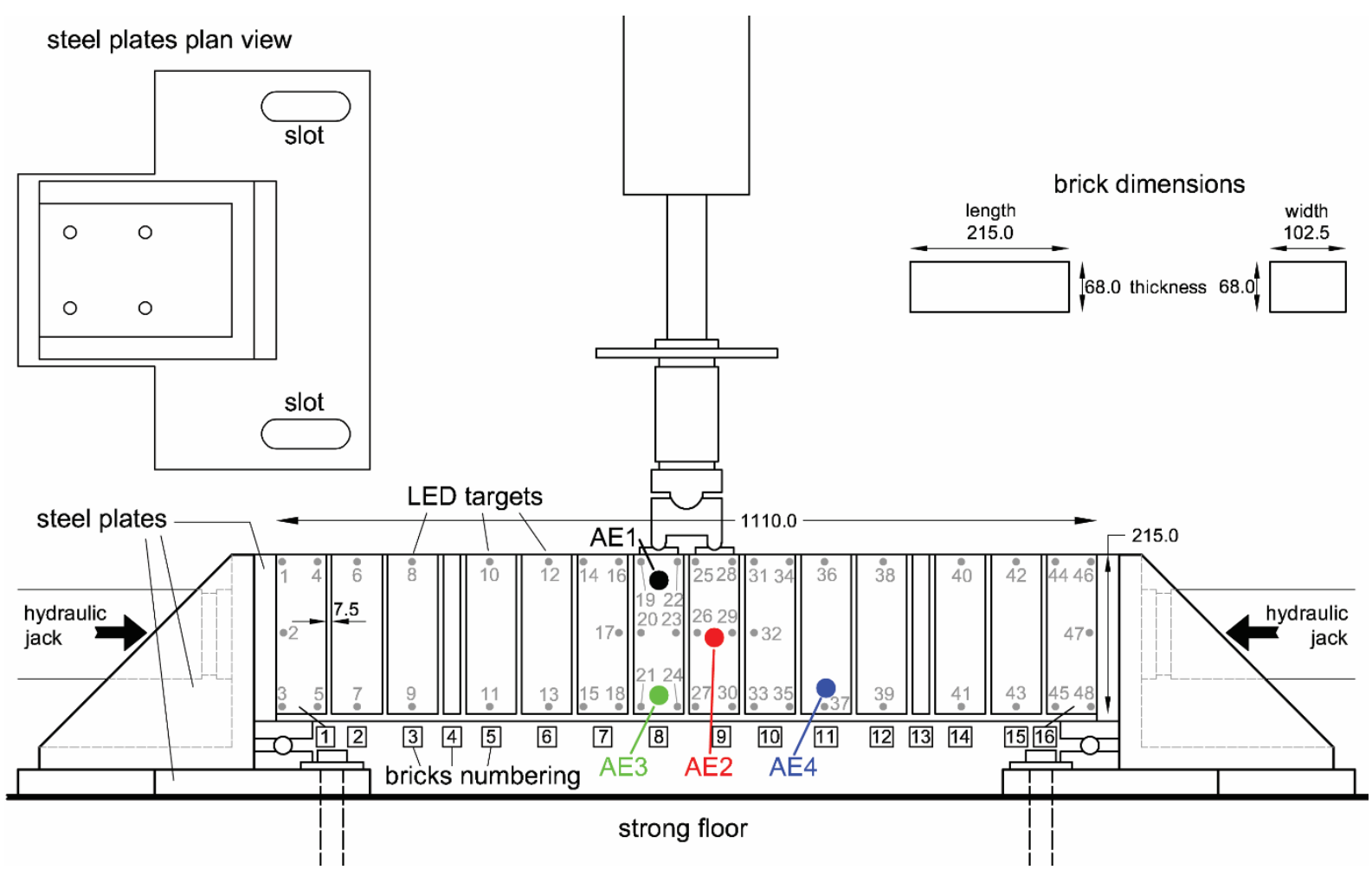

Fig. 3. Schematic representation of the front side of the masonry specimens showing the location of the sensors. 
This study focuses on the progressive damage in masonry due to cyclic train loading. The arch barrels in the Marsh Lane Viaduct (Fig. 1-left) have cracks that develop both in the longitudinal and transverse direction of the bridge $[4,5]$, which is the result of dynamic response mechanisms in both directions, as discussed in [21]. Fibre Bragg grating sensors, which measure surface strain in $1 \mathrm{~m}$-wide areas, indicate a typical fluctuation of the dynamic strain in the order of $\pm 50 \mu \varepsilon$ when typical passenger trains cross the bridge [6]. Note that positive values correspond to relative tensile strain, $\Delta \varepsilon$, whereas negative to relative compressive strain. The train speed over the bridge is typically in the range of 30$55 \mathrm{~km} / \mathrm{h}(8.3-15.3 \mathrm{~m} / \mathrm{s})$, whereas a typical axle distance of passenger trains ranges from 9 to $16 \mathrm{~m}$. As a result, the train loading causes a dominant dynamic response of the bridge in the frequency range of $0.5-1.5 \mathrm{~Hz}$.

In this study, there was an effort to create a similar stress condition and crack behaviour and monitor the evolution of $A E$ events as damage progresses. The approximately $1 \mathrm{~m}$-long masonry specimens may represent arch sections in the longitudinal direction of the bridge, or sections of the barrel vault in the transverse direction. In either case, these sections are well confined inside the body of the arch, providing constraints that resist the opening of the crack. In the transverse direction this is enhanced with the presence of steel ties $[4,5,21]$. In the longitudinal direction, the arch sections are under compression due to the arch thrust. A representative value of the compressive stress in the Marsh Lane arch due to backfill is estimated to be around $0.5 \mathrm{MPa}$.

Based on the above, the two ends of the masonry specimens were confined between an array of steel plates, as shown in Figs 2 and 3. Fig. 3 (top-left) shows the plan view of the steel plates. The plates are bolted on the strong floor through slots that allow them to move only in the specimen's longitudinal direction. This force (and displacement) in this horizontal direction is controlled by hydraulic jacks. Before the application of the vertical load, the masonry panels were pre-compressed with a $10 \mathrm{kN}$ horizontal load. This results in compressive stresses of approximately $0.5 \mathrm{MPa}$, which is the representative stress of the Marsh Lane arches. After the application of the horizontal force, the hydraulic jacks were locked in place to prevent any movement in the horizontal direction.

The selected vertical load history is shown in Fig. 4. The force is applied downwards. The actuator was operated in force-control to more realistically simulate train loading. The vertical load, $F_{v}$, can be represented as the sum of a static component, $F_{v s}$, and a dynamic component, $F_{v d \text { : }}$

$$
F_{v}=F_{v s}+F_{v d}
$$

The static component, $F_{v s}$, is gradually increased in steps of $2 \mathrm{kN}$. The dynamic component, $F_{v d}$, is an additional sinusoidal load from 0 to $2 \mathrm{kN}$, as shown in Fig. 4. In every step of $F_{v s}, 1000$ load cycles are performed. The frequency of the dynamic load is $1 \mathrm{~Hz}$, which is a representative value for the dynamic response of the bridge caused by the train loading. The process is repeated in each step until collapse occurs. The $2 \mathrm{kN}$ load step increase of $F_{v s}$ and the $2 \mathrm{kN}$ peak-to-peak amplitude of $F_{v d}$ were selected during a calibration test of the actuator, where an identical masonry specimen was used. During the calibration test, a $2 \mathrm{kN}$ dynamic load was causing strains close to $\pm 50 \mu \varepsilon$, which is the representative value measured in the bridge with fibre Bragg grating sensors at the central bottom fibres of the uncracked masonry.

The motivation to study the acoustic emission behaviour of masonry at multiple damage levels arises from the big variety of crack widths observed in Marsh Lane Bridge, ranging from hairline to $2 \mathrm{~cm}$-wide cracks. In other areas of the bridge, crushing of bricks is observed due to high concentration of compressive stresses. Clearly, there has been a significant redistribution of stresses during the long deformation history of the structure.

The selection to limit the cycles to 1000 per load step was due to limitations of the available loading system, which could not be left running unattended. By using the $2 \mathrm{kN}$ static load step increase it took 
approximately 8 hours (one working shift) to complete each test. High-cycle fatigue testing is of interest for future research.

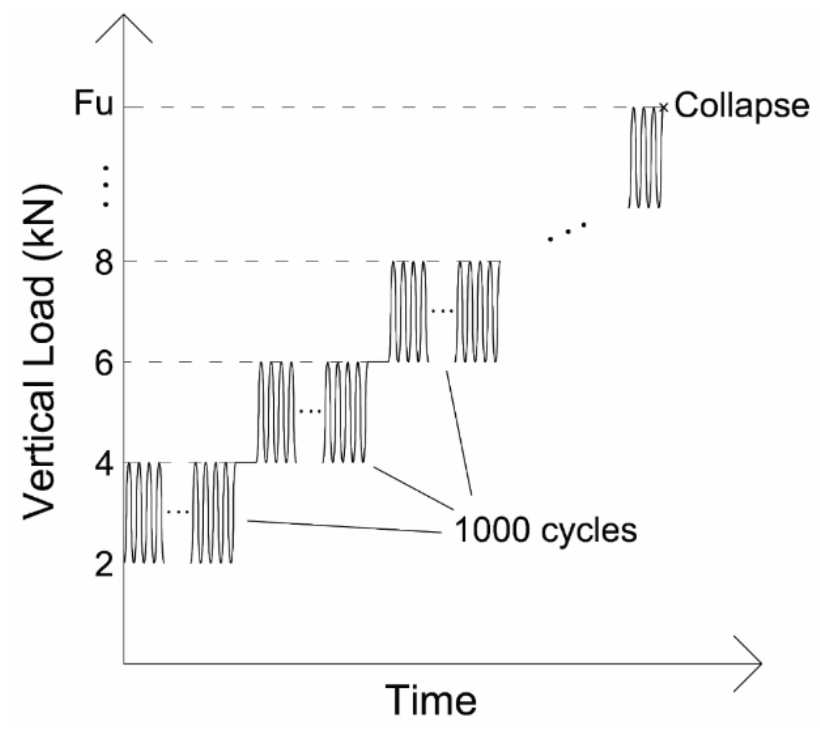

Fig. 4. Representation of the vertical load history.

\subsection{Monitoring system}

Fig. 3 presents schematically the front side of the masonry beam, together with the location of the sensors. Four MISTRAS R6 $\alpha$ general purpose AE sensors were used, with $60 \mathrm{kHz}$ resonant frequency and $35-100 \mathrm{kHz}$ operating frequency range. The signals were amplified at $40 \mathrm{~dB}$ by using general purpose voltage preamplifiers. Three sensors, AE1-AE3, shown in Fig. 3 with black, red and green circles, are distributed along the central joint, to monitor the propagation of the middle crack. Two sensors are installed at the left of the central joint and one at the right. Having sensors at both sides of the joint, where a discontinuity is expected to form as the crack propagates, permits to monitor cracking events on both sides. In this central area of the beam, bending-induced damage is expected to dominate as the load increases. The fourth sensor, AE4, shown in Fig. 3 with a blue circle, was installed two bricks away from the central joint, to better capture shear cracking events that are expected to occur away from the center.

Fig. 5 presents an $A E$ event recorded during the tests. The signal, which was amplified with a gain of $40 \mathrm{~dB}$, is shown in Volts. Fig. 5 shows some basic parameters (features) of an AE waveform, such as the amplitude of the signal, the duration of the event (or duration of a hit) and the rise time. The total number of times the signal exceeds a threshold level above the signal noise is the Number of Counts (also reported as RDC-ring-down counts). These parameters can be related to material deterioration and damage severity.

The selection of the data logging method defines the data processing approach to be used, which can be divided in two categories [22, 23]; the parameter-based (or feature-based) approach and the signalbased (or waveform-based) approach. In the first case, only signal features are stored. This approach considerably reduces the amount of data and is suitable for long-term monitoring of large-scale structures. In the second case, the whole signal is stored, allowing more detailed post-processing analysis with the use of waveform processing algorithms. This approach requires sufficient storage space and computational power due to the high sampling rate, which is usually on the order of $\mathrm{MHz}$ per sensors. 


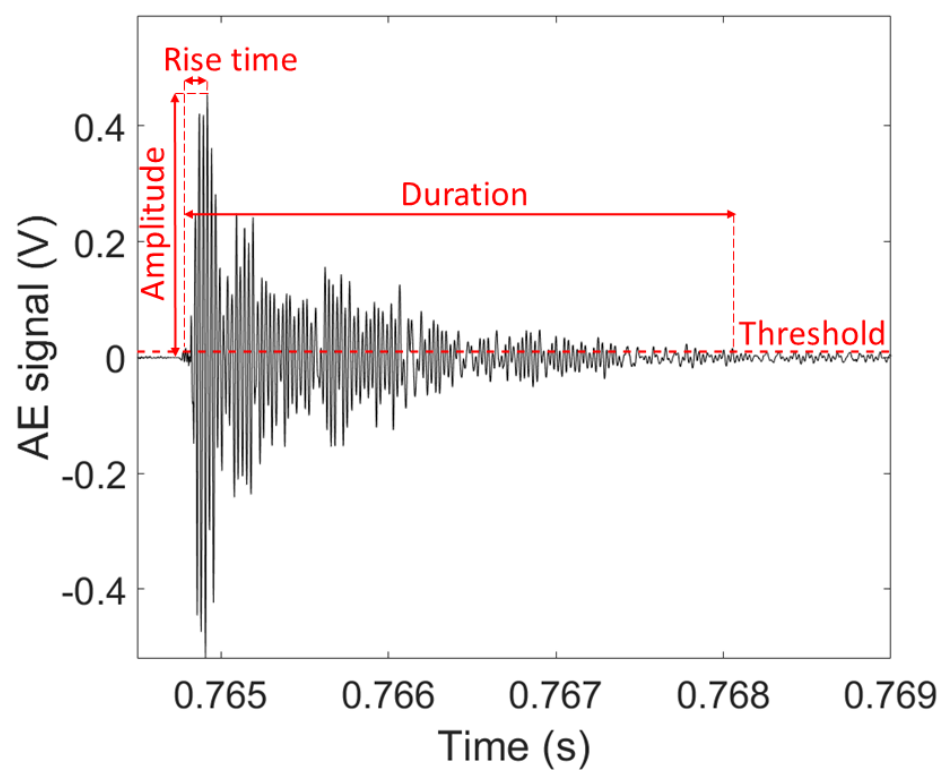

Fig. 5. AE waveform parameters.

An in-house Data Acquisition (DAQ) system similar to the one installed in the Marsh Lane Viaduct (Fig. 1) was developed for this study, which can operate in both parameter-based and signal-based modes. A National Instruments real-time embedded industrial controller was used for the four AE sensors, offering up to $1 \mathrm{MHz}$ sampling rate per channel. The maximum voltage that the system can record is $10 \mathrm{~V}$, which corresponds to $100 \mathrm{~dB}$. The core operations are performed in the FPGA (Fieldprogrammable gate array) chip of the controller. LabVIEW FPGA was used to configure the chip for the system triggering, for processing the signals and buffering the data to the host PC. More specifically, the triggering threshold was set at $40 \mathrm{~dB}$, slightly above the signal noise (see also Fig. 5). FPGA signal processing included baseline correction and logging peaks and counts of signals above the $40 \mathrm{~dB}$ threshold. This data is sufficient to partially reconstruct the signal waveform, while considerably reducing the required data storage. The controller is able to buffer both the signal waveform and features (peaks and counts) in segments of $1 \mathrm{sec}$ after triggering. For the long-term monitoring of Marsh Lane Bridge, the feature-based mode is selected, whereas during the laboratory tests both modes were used simultaneously.

Silicone grease was used to couple the AE sensors to the masonry surface. Hsu-Nielsen Pencil-Lead Break tests were performed to verify the sensors coupling and determine the AE signal attenuation of the specimens. Fig. 6 shows the amplitude of signals of the central sensor AE2 from the 1st specimen, produced by 10 pencil-lead breaks at the center of consecutive bricks away from the sensor, and in particular, from brick \#9 to \#16 (see also Fig. 3). Fig. 6 also offers three alternative signal attenuation curves based on linear regression, exponential regression, which is commonly found in literature, and cubic regression, which appears to better represent the test data. The wave propagation velocity along the longitudinal direction was measured to be $3306 \mathrm{~m} / \mathrm{s}$.

The 48 small grey dots in Fig. 3 show the location of LED targets of a triple-camera dynamic tracking measurement system. The system tracks the space coordinates of the LED targets. The camera was placed at $3 \mathrm{~m}$ distance from the front side of the specimen, and the resolution achieved was $10 \mu \mathrm{m}$. The sampling rate was $1 \mathrm{kHz}$. Each brick, apart from the two thinner at the 1/4 of the span, has at least two targets to monitor its in-plane movement and to approximate the rigid body motion (rotation and displacement) after large displacements between bricks have occurred. The bricks at the center of the span, where more damage is expected, are densely monitored.

The back side of the specimen is clear of sensors, in order to conduct Digital Image Correlation (DIC) analysis. It is noted that, during the masonry construction, a formwork was used to align the back side 
of the specimen's bricks. After maturing of masonry, the formwork was removed, leaving mortar stains on the bricks. The back side of the brick surfaces was rough, and as a result, the stains created a speckle pattern, which was used for the DIC. For this analysis, a digital camera was used to take photos with dimensions of $5472 \times 3648$ pixels at 72 dpi, every 20 seconds.

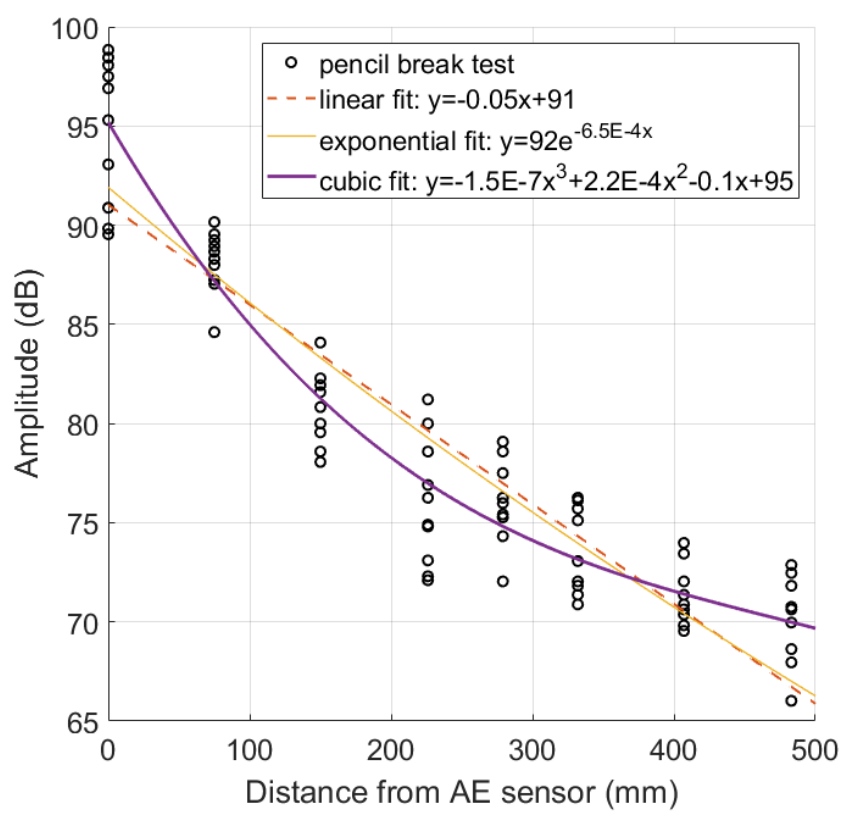

Fig. 6. AE signal attenuation.

\section{Results}

4.1. Description of damage propagation

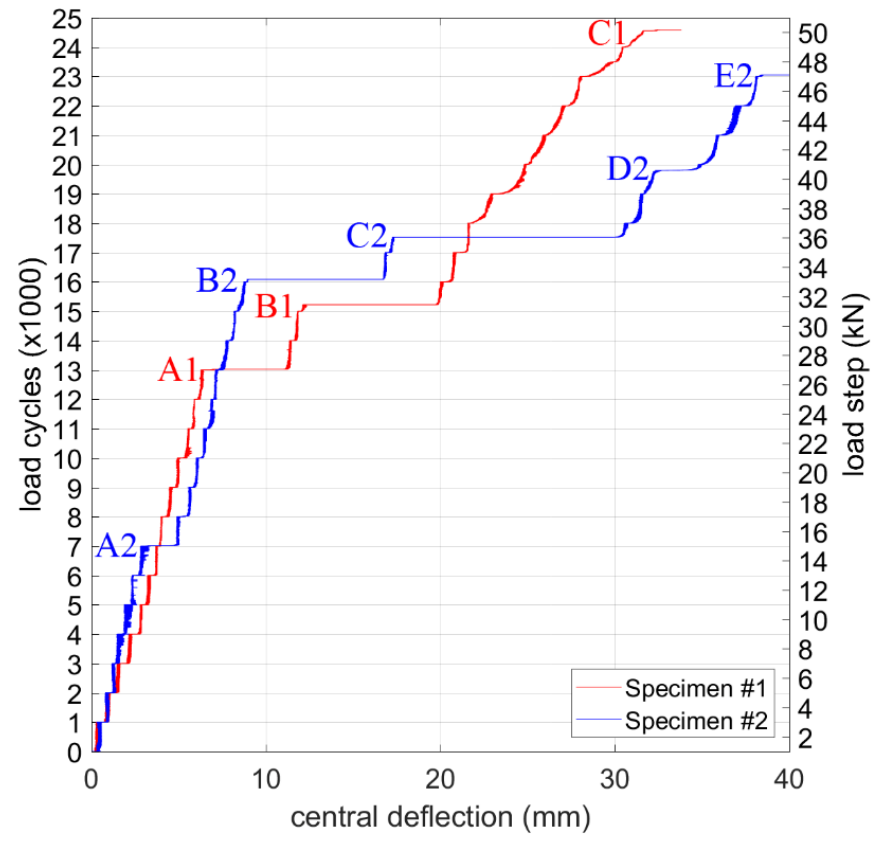

Fig. 7. Force-displacement diagram for the two specimens.

This section presents results from two unreinforced brick masonry beams, named from now on as specimen \#1 and specimen \#2, subjected to horizontal compressive force and gradually increasing cycling bending loading until collapse. Fig. 7 compares the central deflection of specimen \#1, shown 
with a red line, with the central deflection of specimen \#2, shown with a blue line. The selection of the number of load cycles as the main vertical axis at the left hand side instead of the load step, $F_{v s \text {, }}$ which is shown at the right hand side, is deliberate. The horizontal grid lines, which follow the marks of the main vertical axis on the left, define the beginning and end of each load step. This is critical for the interpretation of the results that follow. The marks of the secondary vertical axis on the right are intentionally located between the horizontal grid lines. Critical damage events that correspond to sudden increases in central deflection are numbered in the diagram. These events mark changes in damage modes and structural behaviour, as discussed below. Collapse occurred at $50 \mathrm{kN}$ and $48 \mathrm{kN}$ for specimens \#1 and \#2, respectively.

\subsubsection{Specimen \#1}

Fig. 8 presents images of the back side of specimen \#1 at zero vertical load (Fig. 8a) and right after the major events $\mathrm{A} 1, \mathrm{~B} 1$ and $\mathrm{C} 1$ (Figs. 8b-d), together with DIC displacement vectors showing the deformation history from one state to the following. 15 vectors are shown per brick. The head of the vectors is indicated with red colour. For clarity, the size of the vectors is scaled up by a factor of 3 .

Fig. 9a plots the absolute displacement of the actuator (central deflection), together with selective relative distances of LED sensors, shown in Fig. 3. In particular, "x27-x24" corresponds to the change in the horizontal distance between LEDs \#24 and \#27, to monitor the crack opening of the mid-span joint between bricks \#8-9; "y11-y15" corresponds to the change in the vertical distance between LEDs $\# 11$ and \#15, to track vertical sliding and shear failure in the region of bricks \#5-\#7; and "y45-y41" corresponds to the change in the vertical distance between LEDs \#41 and \#45, to track vertical sliding and shear failure in the region of bricks \#14-\#16. Fig. 9b is similar to Fig. 9a, except that relative displacements, rather than absolute displacements, are presented for each load step. Below, a detailed description of the damage propagation in specimen \#1 is offered.

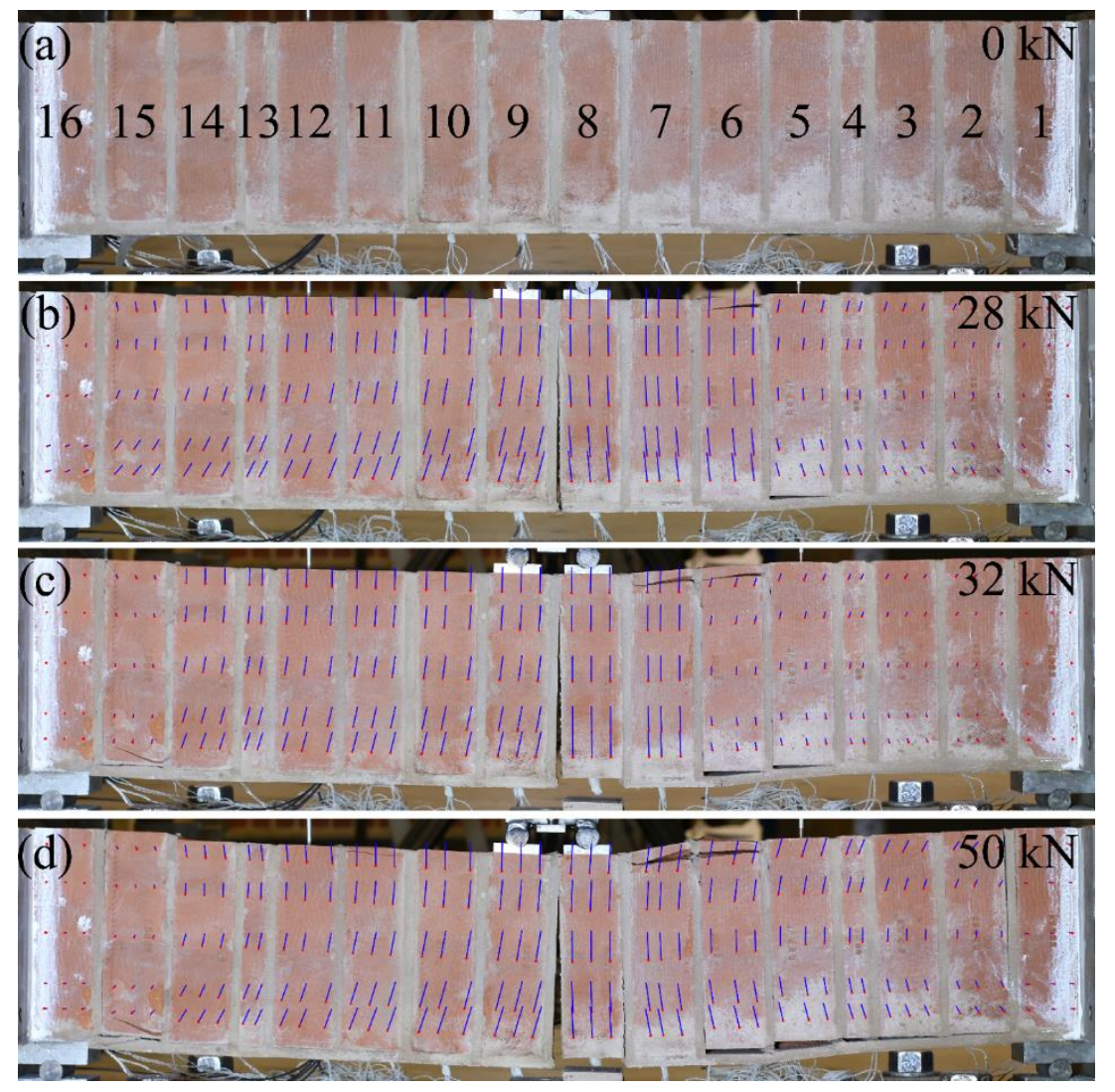

Fig. 8. (a) Back side of specimen \#1 with bricks numbering. (b) Photo after event A1 with DIC displacement vectors from 0 to 14000 cycles. (c) Photo after event B1 with DIC from 14001 to 16000 cycles. (d) Photo after collapse C1 with DIC from 16001 to the end of test. 


\section{Specimen \#1}

(a)

load step $(\mathrm{kN})$

2468101214161820222426283032343638404244464850

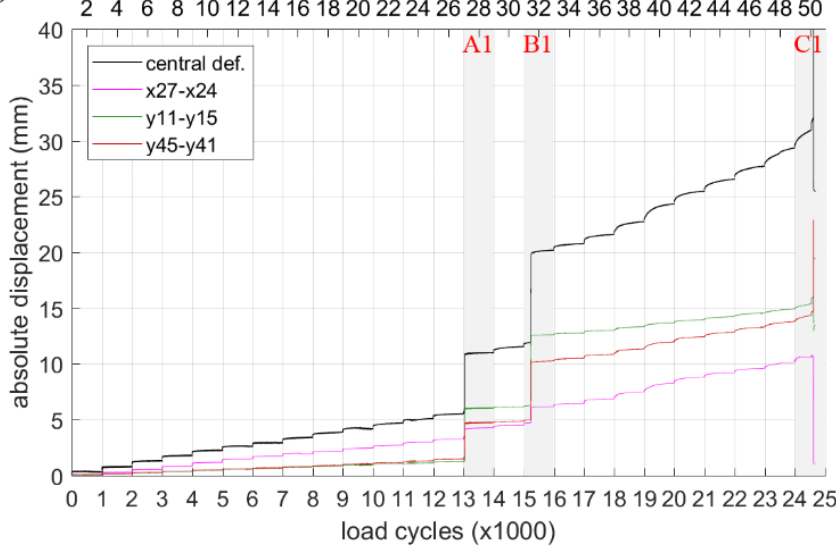

(b)

load step $(\mathrm{kN})$

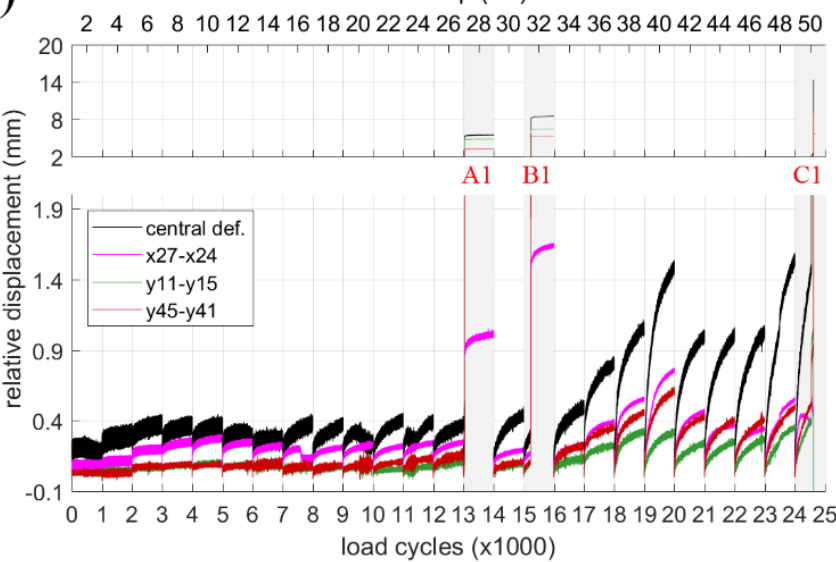

(c)

load step $(\mathrm{kN})$

$\begin{array}{lllllll}2 & 4 & 8 & 101214161820222426283032343638404244464850\end{array}$

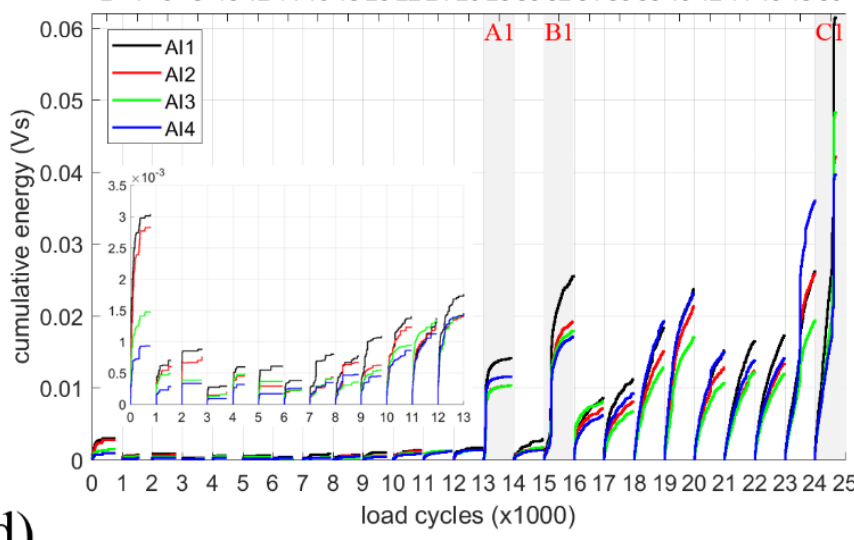

(d)

load step $(\mathrm{kN})$
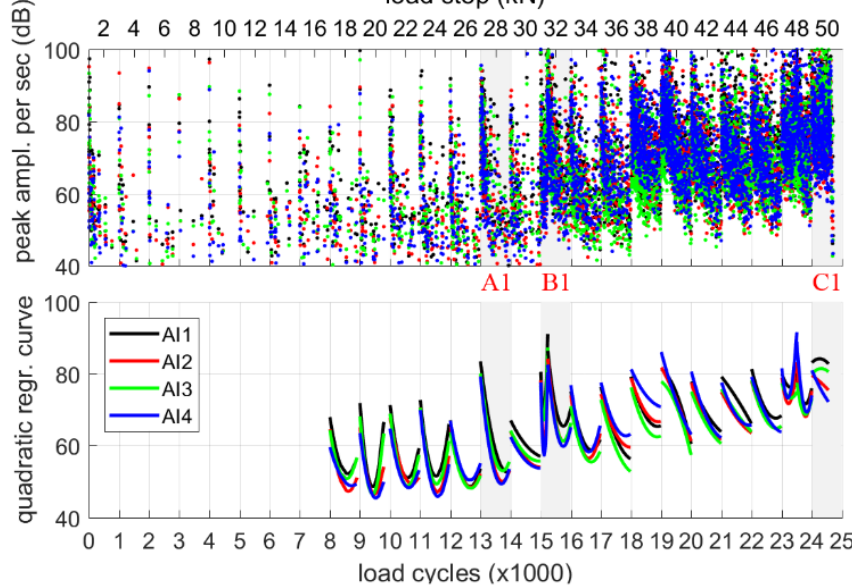

\section{Specimen \#2}

(e)

load step $(\mathrm{kN})$

246681012141618202224262830323436384042444648

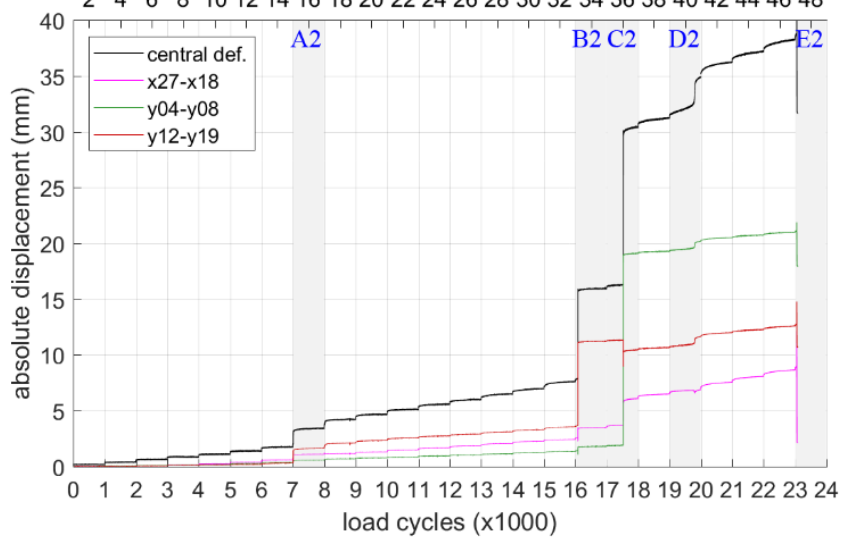

load step $(\mathrm{kN})$

(f)

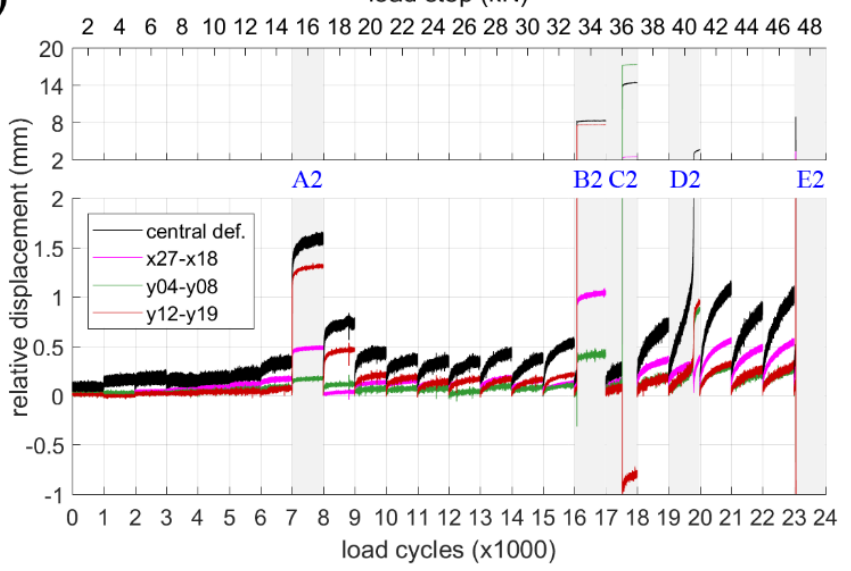

(g)

load step $(\mathrm{kN})$

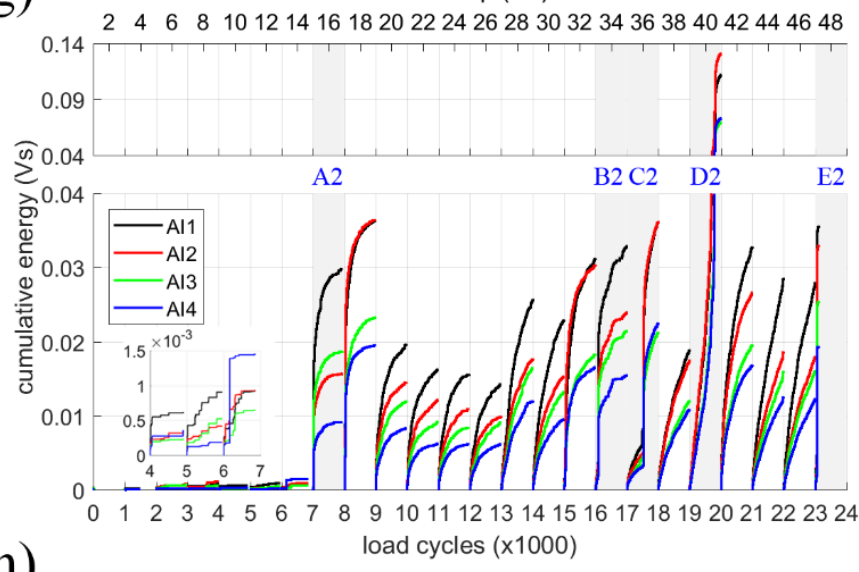

(h) load step $(\mathrm{kN})$

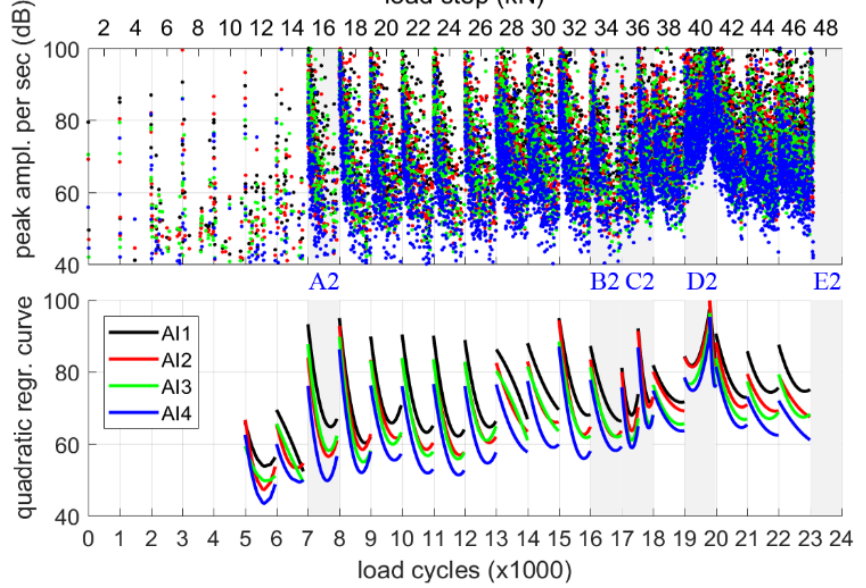

Fig. 9. Left column-Specimen \#1: (a) Displacement history of central deflection and distance change between selective LED targets; (b) same as (a), but showing relative displacement for each load step; (c) cumulative AE energy; (d) peak AE signal amplitude per second (top) and quadratic regression curve (bottom). Right column-Specimen \#2: (e-h) description as per (a-d). 
- Before event A1 $\left(F_{v s}=0-28 \mathrm{kN}\right)$ : The gradually increasing bending moment at the centre of the specimen resulted in a gradual propagation of a bond failure crack between brick \#8 and the \#8-9 mortar joint. The crack started to be visible at $F_{v s}=8 \mathrm{kN}$ at the bottom of the mid-section and gradually propagated upwards, as shown in the centre of Fig. $8 \mathrm{~b}$. The specimen behaves as a 3-hinge mechanism with compressive stress concertation at the top in the mid-span and the bottom in the supports.

- Event A1 ( $\left.F_{v s}=28 \mathrm{kN}\right)$ : High compressive stress at the top of the mid-span, combined with shear at the quarter span, resulted in sudden crushing of the top of brick \#6 with simultaneous sliding in joint \#56 , as shown in Fig. 8 b.

- Event B1 $\left(F_{v s}=32 \mathrm{kN}\right)$ : A similar damage mechanism as Event A1 occurred (see Fig. 8c). Now the top of the neighbouring brick \#7 crushed, with simultaneous sliding in joint \#6-7, and the bottom of brick $\# 15$ crushed, with simultaneous sliding in joint \#14-15. In addition, mortar crushing is now visible at the top of joints \#7-8, \#8-9 and \#9-10.

- Collapse $\mathrm{C} 1\left(F_{v s}=50 \mathrm{kN}\right):$ A sudden shear failure occurred in the region between brick \#11 and \#15 (see Fig. 8d). Deterioration in this region became visible after load step $F_{v s}=36 \mathrm{kN}$. In particular, compressive cracking started to form at the top of brick \#11 and further developed at the bottom of brick \#15. This mechanism continued until event $\mathrm{C} 1$, where the bottom of brick \#15 crushed, with simultaneous sliding in joint \#14-15, as shown in Fig. $8 \mathrm{~d}$. After $\mathrm{C} 1$, the specimen couldn't sustain any more load and the test was terminated.

The above major events, A1, B1 and C1, are easily distinguishable in Figs. 9a and 9b. The corresponding load steps are shown with grey shaded areas. Fig. 9a shows that, macroscopically, the deflection is linear with the vertical load up to A1. The same holds for the "x27-x24" mid-span crack opening. The linear trend in " $\mathrm{y} 11-\mathrm{y} 15$ " and " $\mathrm{y} 45-\mathrm{y} 41$ " is explained by the gradual rotation of the two half-spans of the specimen due to the 3-hinge mechanism. The jumps in the diagram at $\mathrm{A} 1, \mathrm{~B} 1$, and $\mathrm{C} 1$, are due to the joint sliding discussed before.

Fig. $9 \mathrm{~b}$ compares the relative displacements that occurred during the different load steps. In principle, the specimen deforms faster during the first cycles at each load step, while the deformation rate gradually drops as the number of cycles increases, unless a sudden shear damage event happens. Local shear failure happened suddenly during the tests, either at the beginning (e.g. A1) or during the load step (e.g. B1, C1). This result highlights that by only using sensing or surveying technologies that measure strain or displacement, it is hard to predict when brittle shear failure will occur.

\subsubsection{Specimen \#2}

Fig. 10 corresponds to Fig. 8, but now showing specimen \#2 after major events A2-E2. Note that some wild vectors occur in this last image, Fig. 10f (collapse state), where surface spalling or cracking prevents a few points from being correctly tracked.

Figs. 9e and 9f are similar to Figs. 9a and 9b, but correspond to specimen \#2. "x27-x18" corresponds to the change in the horizontal distance between LEDs \#18 and \#27 and monitors the crack opening of the mid-span joint \#8-9 and the neighbouring joint \#7-8; "y04-y08" corresponds to the change in the vertical distance between LEDs \#4 and \#8 to track vertical sliding and shear failure in the region of bricks \#1-\#3; and "y12-y19" corresponds to the change in the vertical distance between LEDs \#12 and $\# 19$, to track vertical sliding and shear failure in the region of bricks \#6-\#8. Below, a detailed description of the damage propagation in specimen \#2 is offered.

- Before event A2 ( $\left.F_{v s}=0-16 \mathrm{kN}\right)$ : A bond failure crack between brick \#9 and the \#8-9 mortar joint gradually develops upwards. The crack started to be visible at the $8 \mathrm{kN}$ load step at the bottom of the mid-section joint, similar to specimen \#1. 

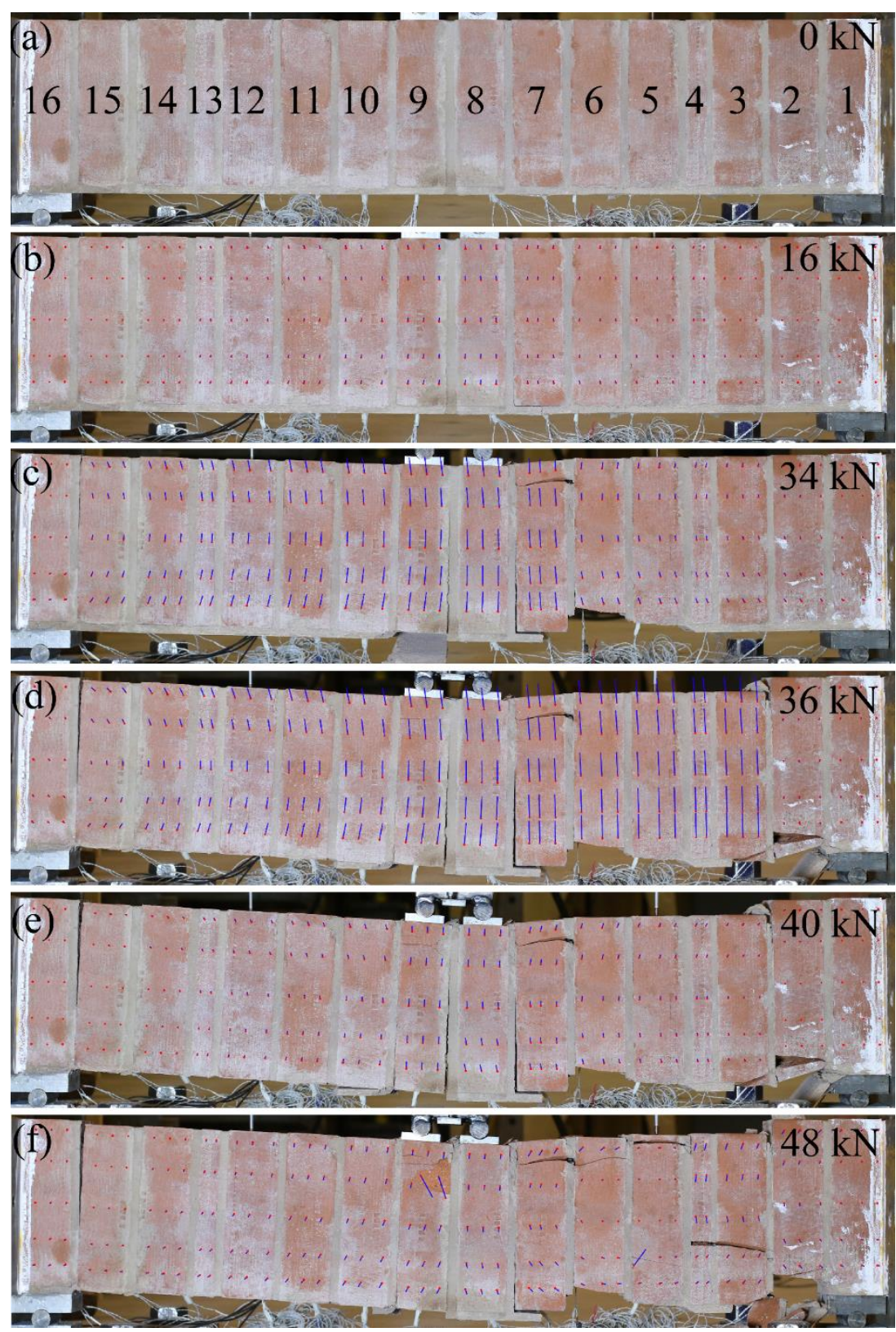

Fig. 10. (a) Back side of specimen \#2 with bricks numbering. (b) Photo after event A2 with DIC displacement vectors from 0 to 8000 cycles. (c) Photo after event B2 with DIC from 8001 to 17000 cycles. (d) Photo after event C2 with DIC from 17001 to 18000 cycles. (e) Photo after event D2 with DIC from 18001 to 20000 cycles.

(f) Photo after collapse E2 with DIC from 20001 to the end of test.

- Event A2 $\left(F_{v s}=16 \mathrm{kN}\right)$ : Crushing of mortar at the top of joint \#7-8, resulted in joint sliding between bricks \#7 and \#8. A bond failure bending crack appears in joint \#7-8 at the bottom, corresponding to closing of the neighbouring mid-span crack in joint \#8-9, which was previously developed.

- Event B2 $\left(F_{v s}=34 \mathrm{kN}\right)$ : Sudden local shear failure occurs in the region of the bricks \#6-\#8. The top of brick \#7 and bottom of brick \#6 crushed. A bond failure due to bending appears at the top of joint \#1516. Fig. 10c shows the two bond failure bending cracks in joints \#7-8 and \#8-9 that were gradually developing during the previous load steps.

- Event C2 $\left(F_{v s}=36 \mathrm{kN}\right)$ : Crushing at the bottom of bricks \#2 and \#3 is followed by a sudden sliding failure in the joint between the two bricks. Bending cracks at joints \#7-8, \#8-9, \#15-16 continue to open, as shown in Fig. 10d. Figs. 10c and 10d show that a mixed mechanism has been developed, with the \#1\#8 brick region suffering from shear, and the \#9-\#16 brick region forming a two-hinge mechanism. 
- Event D2 $\left(F_{v s}=40 \mathrm{kN}\right)$ : Another jump downwards of the specimen occurs (see Fig. 10e). The jump is less sadden, compared to the other events. The same mixed mechanism further develops and bending cracks further open.

- Collapse E2 $\left(F_{v s}=48 \mathrm{kN}\right)$ : Extensive brick crushing in the area between bricks \#3 and \#8 due to shear suddenly occurs. The specimen can no longer sustain load and the test is terminated.

The above major events, A2- E2, are easily distinguishable in Figs. 9e and 9f. Similarly to Fig. 9b, Fig. 9f shows that the specimen deforms faster during the first cycles at each load step, while the deformation rate gradually drops as the number of cycles increases, unless a sudden shear damage event occurs. Local shear failure again happened suddenly during the tests, either at the beginning (e.g. B2 and E2) or during the load step (e.g. C2). Instead of a sharp jump, the gradual deterioration of D2 is reflected in the smooth curve in Fig. 9f. As in the first specimen, it would have been difficult to predict brittle shear failure by relying only on strain or displacement monitoring.

\subsection{AE Feature-based analysis}

The in-house AE system developed in this study for field infrastructure monitoring and lab testing can perform feature-based AE analysis. This typically includes the study of the evolution of signal features such as (i) the number of counts, (ii) the energy, and (iii) the amplitude of the signals. For (i), the number of counts for each 1-second data segment are directly calculated in the FPGA of the DAQ system through LabVIEW programming. For (ii), the peaks of the signal, also retrieved directly from the DAQ, are used to calculate the signal energy per second, which is defined as the area under the waveform envelope and above the noise threshold. The units are V-s (Voltage multiplied by second). (i) and (ii) are typically presented in the form of cumulative plots. For (iii), the maximum signal amplitude among all events contained in the 1-second segment is expressed in the decibel scale. The voltage signals are converted in the decibel scale by using the following equation:

$$
d B_{A E}=20 \log _{10}\left(\frac{V}{V_{o}}\right)-G_{p}
$$

where, $V$ is the amplitude of the preamplified signal or output of the system expressed in microvolts, $V_{o}$ is the reference voltage equal to $1 \mu \mathrm{V}$, and $G_{p}$ is the preamplifier gain equal to $40 \mathrm{~dB}$.

In the results that follow, the evolution of cumulative energy and amplitude of AE signals is presented. The analysis based on cumulative number of counts offered very similar patterns to cumulative energy and is omitted for the sake of brevity.

\subsubsection{Specimen \#1}

Fig. 9c presents the cumulative energy for specimen \#1 of the four AE sensors, AE1-AE4, shown in Fig. 3 , for each load step. The plot presents similarities in shape with the relative displacement plot of Fig. $9 \mathrm{~b}$, showing that, in principle, increase in deformation is accompanied by increase in acoustic emissions. Fig. 9d-top presents the peak signal amplitude per second for the four AE sensors, while Fig. 9d-bottom presents the best fit quadratic regression curves that correspond to Fig. 9d-top for each load step, with the exception of the load steps from 0 to 8000 cycles, where the small number and distribution of the $\mathrm{AE}$ events did not permit to construct the curves.

One may observe two main stages in Fig. 9c. The first stage is before the A1/B1 shear failure, from 0 to 13000 cycles, which is characterised by low AE activity. The results of the low activity stage are offered separately in the enlarged scale plot inside the figure. The A1/B1 shear failure marks a transition phase, where the specimen enters in the second main stage with significant AE activity until collapse. A more detailed description of these stages is offered below:

- Low AE activity stage (before A1/B1): During this stage, the only visible crack is the bond failure crack in the mid-span joint that propagates upwards. Clearly, the bond failure crack generates significantly 
less $A E$ compared to other damage modes that occurred later in the test. The intact specimen generated more AE energy and counts in the first load step (from 0 to 1000 cycles), compared to the later load steps of this stage, as shown in the enlarged scale plot. In the first load step, 0-1000 cycles, the sensors closer to the compression zone, AE1 (black line), is more active compared to the AE2 (red line) in the mid-height and the AE3 (green line) in the tensile zone. The AE4 (blue line), which is further away from the mid-span joint, is less active. The same holds for all load steps in this stage. Fig. 9d-top shows that the AE event frequency and amplitude is higher in the first cycles of each new load step, and also increases as $F_{v s}$ increases. The AE activity is clearly building up before the A1 event, as shown in Figs. 9c-d, especially from 7000 to 13000 cycles. Interestingly, the relative displacement plot in Fig. $9 \mathrm{~b}$ shows a relatively constant behaviour for all load steps before the A1 event, without offering any warning indication. In contrary, the $\mathrm{AE}$ sensors were picking up change in the cracking rate before the A1 brittle failure. Lastly, the shape of the quadratic regression curves in each load step of Fig. 9dbottom show that in the load steps after the 8000 cycle and before A1, the AE event amplitude doesn't drop constantly, but after a number of cycles the amplitude increases again, indicating material fatigue.

- Transition (A1/B1): The shear local failures, A1 and B1, are brittle failure events that generated considerably more AE energy compared to the previous load steps, as shown clearly in the corresponding shaded areas of Fig. 9c. Figs. 8b and 8c show that the top of bricks \#6 and \#7 crushed in the compression zone, in the vicinity of sensor AE1, which explains why this sensor has recorded more AE energy.

- High AE activity stage (after A1/B1): As discussed in Fig. 8c and 8d, after B1 and before collapse C1 the region between bricks \#11 and \#15 suffers from gradually increasing shear. The sensor AE4 (blue line) which was the least active in the previous steps, is now recording more AE activity, as shown in Fig. 9c. This is because the AE4 sensor is the closest one to the \#11-15 brick region. This type of failure mode, diagonal shear failure, generates significant AE activity. From 16001 to 20000 cycles, the AE activity is building up, together with the deformation of the specimen, shown in Fig. 9b. From 20001 to 23000 the specimen has been converted to a 3-hinge mechanism and its stability is relying mostly on the compression strength of the hinges. This offers a stable behaviour during these cycles, though with continued emissions throughout the load cycle, demonstrating continued fatigue damage with cycling. One load step before collapse, from 23001 to 24000 cycles, the deformation becomes comparable again with cycles 19001 to 20000, as shown in Fig. 9b. However, there is unprecedented AE activity shown in Fig. 9c, which is a warning for the $\mathrm{C} 1$ collapse that follows. The final shear failure which resulted in the total collapse, generated even more acoustic emissions. Fig. 9d shows that during the high $A E$ activity stage, the frequency and the amplitude of $A E$ events is gradually increasing with the increase of $F_{v s}$.

\subsubsection{Specimen \#2}

Figs. 9g and $9 \mathrm{~h}$ are the equivalent to Figs. $9 \mathrm{c}$ and $9 \mathrm{~d}$, but for specimen \#2. As in specimen \#1, two main stages can be observed; a low AE activity stage, from 0 to 7000 cycles, followed by a high AE activity stage. The $A 2$ event marks the transition between the two stages. The transition happens earlier in the second specimen, than the first specimen. Another difference is that after the transition into the high AE activity stage, there are multiple major shear events that happen before the final collapse in the second specimen, whereas in the first specimen the next major shear event led to collapse. A more detailed description of the performance stages of specimen \#2 is offered below:

- Low AE activity stage (before A2): As in specimen \#1, during this stage, the only visible crack is the bond failure crack in the mid-span joint that propagates upwards, which generates significantly less AE compared to other damage modes that occurred later in the test. The A2 event happens due to an early unexpected crushing of mortar at the top of joint \#7-8, which subsequently resulted in joint 
sliding between bricks \#7 and \#8 (see also Fig. 10b). For this damage mode, there was a slight increase of the AE energy before $A 2$ as shown in the enlarged scale plots in Fig. 9g.

- Transition (A2): Sliding failure of joint \#7-8 after the mortar crushing at the top of the joint generated significant increase in the $A E$ energy, as shown in Fig. 9g, marking the transition into the high $A E$ activity stage. The relative deformation plot of Fig. If shows a sharp jump right after 7001 cycle due to the joint sliding, and then the typical decrease in the deformation rate follows. Sensor AE1, which is the nearest sensor in the central compression zone, is the most active, as shown in Figs. 9g and 9hbottom.

- High AE activity stage (after A2): Fig. 9f shows that after the A2 jump, during the 8001-9000 cycles, there is an intense gradual deformation of the specimen downwards. No brittle failure occurs in this load step, but there is a significant AE activity recorded by the sensors, as shown in Fig. 9g. Both deformation and $A E$ activity drops in the following load steps until cycle 13000 , showing that although there is still notable AE activity, indicating continued fatigue damage throughout the cycling at each load step, the specimen enters into a relatively stable condition. This is due to the well confined hinge mechanism that gradually develops. Interestingly, Fig. If doesn't show any notable increase in the deformation rate from cycle 13001 to 16000 , before the next major event, B2, which is a sudden local shear deformation with simultaneous crushing of bricks \#6 and \#7. However, Fig. 9g show that the AE activity builds up before the B2/C2 brittle failure events, offering a clear warning.

Subsequently, event D2 is not a result of a new type of damage and does not exhibit brittle behaviour, but represents a gradual degradation of the existing mechanism during cycling. D2 resulted in the highest AE cumulative energy release. After the D2 event, the deformation rate of the specimen becomes significantly larger as it approaches the collapse E2. Enduring this process, note that AE4 (blue line) remains the least active sensor. As explained in the previous section, the region of bricks \#1-\#8 suffers more from shear than the other half of the beam (bricks \#9-\#16) where AE4 is located. In other words, sensor AE4 is on the opposite side of the beam from the region where extensive shear deterioration takes place. The opposite happened in specimen $\# 1$, where AE4 was the most active during the higher load steps.

\section{3. $b$-value analysis}

To analyse $A E$ signals, several authors have used the analogy between seismic and $A E$ event magnitude-frequency distribution [24-25, 10]. For AE analysis, the following modified GutenbergRichter equation [26] is used:

$$
\log _{10} N=a-b\left(\frac{A_{d B}}{20}\right)
$$

where $N$ is the number of $A E$ events with amplitude higher than $A_{d B}$. Plotting the frequency-amplitude distribution with $A_{d B}$ in the x-axis and $\log _{10} N$ in the $y$-axis, the distribution is expressed with the least square linear regression curve (a straight line), where $a$ is the $\log _{10} N$ value when the curve intersects the $y$-axis and $-b / 20$ is the slope of the curve.

An example is given in Fig. 11, which plots the AE events distribution of specimen \#1 during cycles 6001-7000 (lower curves), which are characterised by low AE activity, and 13001-14000 (upper curves), when the first shear damage event, $A 1$, occurred. In the analysis, the amplitude takes discrete values in steps of $5 \mathrm{~dB}$. Amplitudes greater than $40 \mathrm{~dB}$ are considered, which is the predefined threshold above the signal noise, and below $100 \mathrm{~dB}$, which is the capacity limit of the DAQ system.

In principle, the $b$-value is large when the slope of the distribution line is relatively steep, meaning that the frequency of low-amplitude events dominate over the high-amplitude events, as shown by the lower curves in Fig. 11. As the population of high-amplitude events increases compared to lowamplitude events, the slope becomes shallower and the $b$-value drops, as shown by the upper curves 
in Fig.11. Changes in $b$-value can be associated with damage severity and change in structural performance state as deterioration progresses.

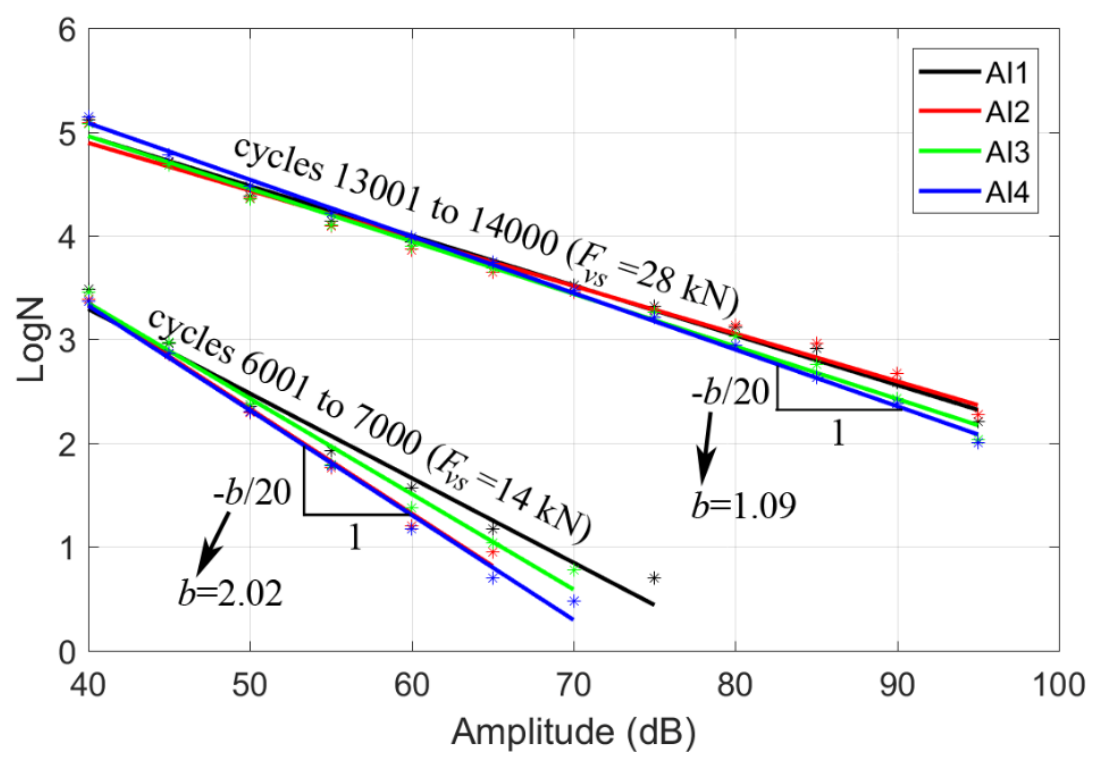

Fig. 11. Frequency-amplitude distribution diagram of the specimen \#1 AE events during cycles 6001-7000 $\left(F_{v s}=14 \mathrm{kN}\right)$ and $13001-14000\left(F_{v s}=28 \mathrm{kN}\right)$

This paper discusses three alternative approaches to calculate the $b$-value based on Eq. (3). The first approach is to follow the common practise of calculating the $b$-value for every $n$ number of events $[25,27]$. A frequently reported value is $n=100$, which is adopted in this study. This is an attractive selection for tests that generate a relative small number of $A E$ events, such as monotonic compression/tension tests. Cyclic/fatigue loading tests however, which more realistically simulate train and traffic loading, generate a larger number of AE events. The second and third approach, proposed in this study, calculate the $b$-value on much larger event populations, which better highlight the severe damage events of the tests, as will be discussed below. The second approach is similar to the first, but calculates the $b$-value over all the events per load step. The third approach is not based on the amplitude distribution of events, like the first and second, but on the distribution of all peaks of the signal per load step. In other words, in Eq. (3), $N$ is the number of all signal peaks with amplitude greater than $A_{d B}$. This last approach doesn't require an $A E$ event recognition algorithm and can be applied directly on streaming raw data.

\subsubsection{Specimen \#1}

Fig. 12a plots the evolution of the $b$-value per 100 events for specimen $\# 1$ for the four AE sensors. Fig. 12a-bottom presents the mean value and standard deviation for each load step, whereas the population of 100-events per load step is offered in Fig. 12a-top. It is noted that there is no significant variation of the standard deviation as the load step and population of events increase. The behaviour of the $b$-value in the low AE activity stage (before $\mathrm{A} 1$ ) can be related to the cumulative energy enlarged plots in Fig. 9c. At the beginning of the stage, the energy is decreasing to reach a minimum at around the 7000 cycles and then rises again before the A1 event. The $b$-value shows a reversed behaviour, reaching a maximum when the $A E$ activity is minimum. During the $A 1$ and $B 1$ shear local failures, the $b$-value reaches a minimum, marking the transition into the high AE activity stage. Near the collapse state, the $b$-value starts to drop again slightly. 
(a)

Specimen \#1

load step (kN)
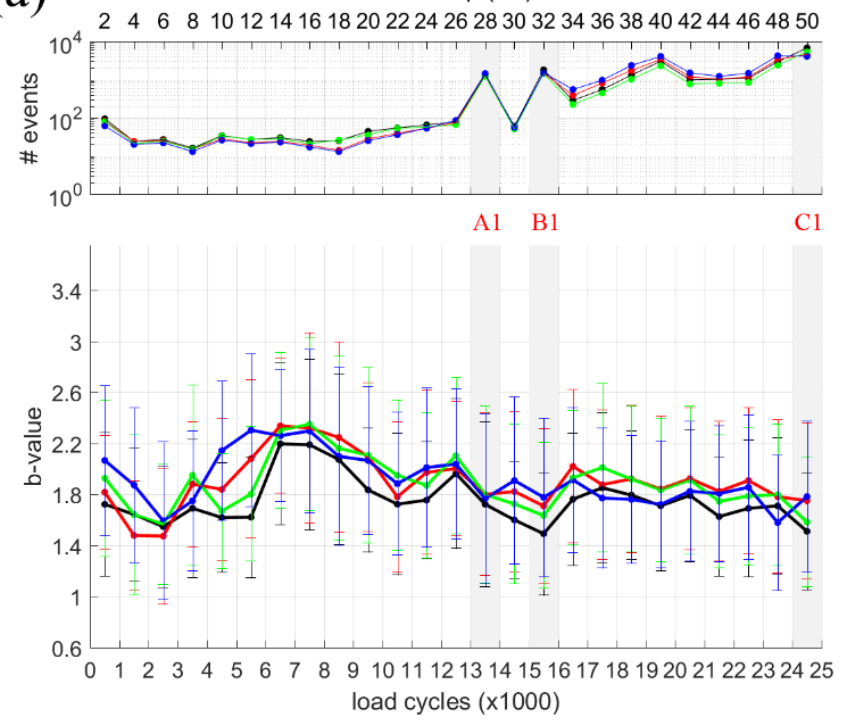

(b) load step $(\mathrm{kN})$

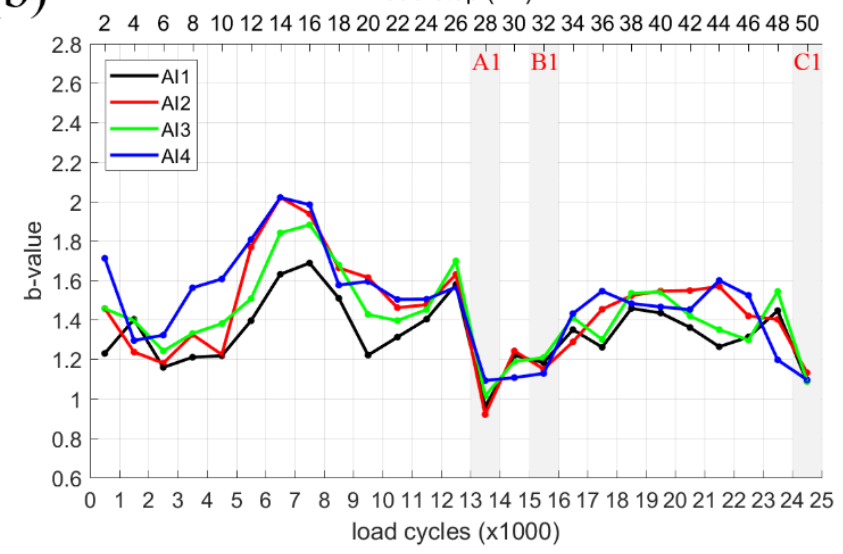

(c)

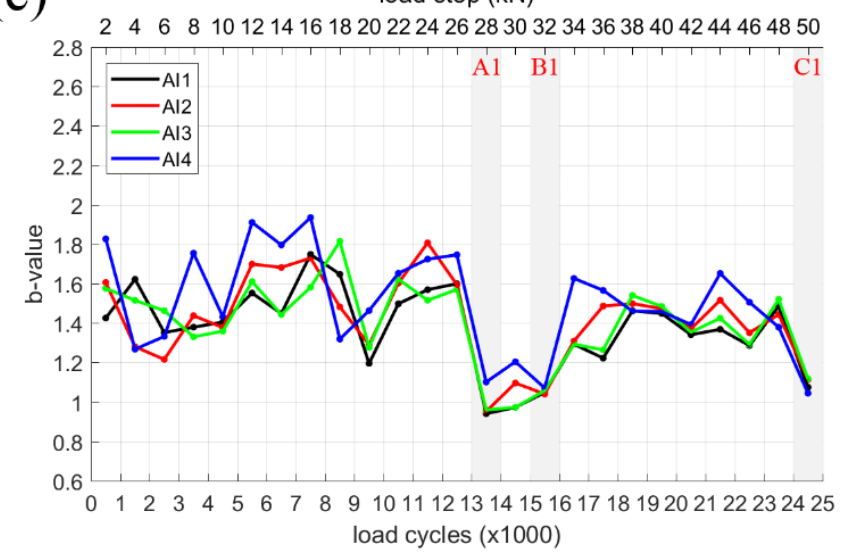

Specimen \#2

(d)

load step $(\mathrm{kN})$
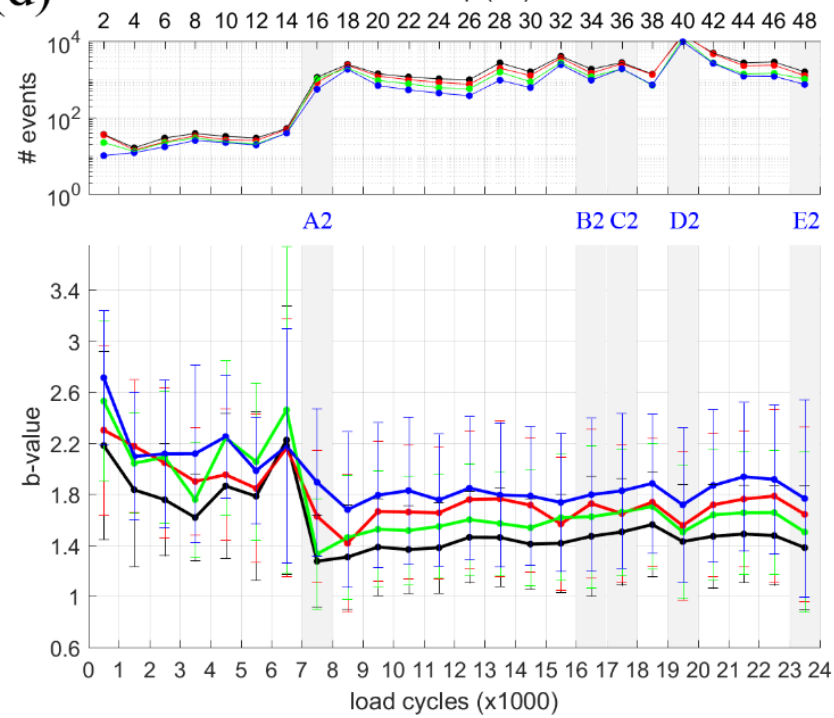

(e)

load step $(\mathrm{kN})$

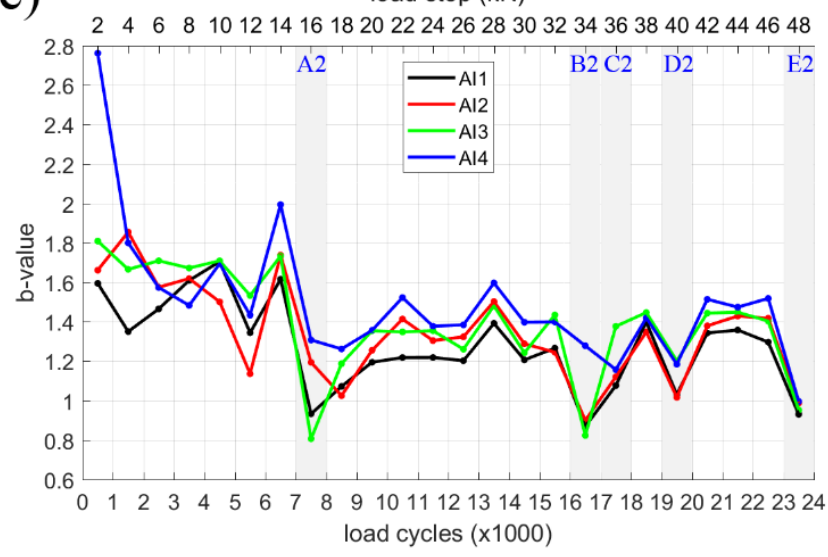

(f)

load step $(\mathrm{kN})$

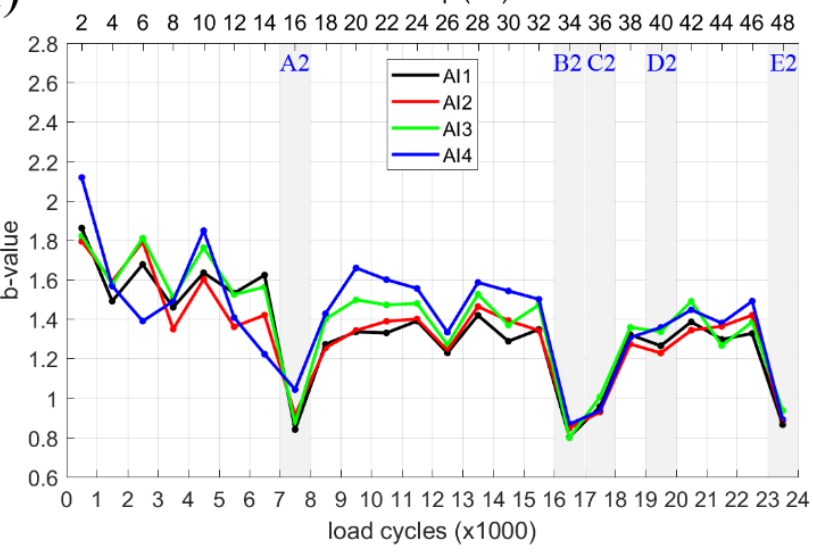

Fig. 12. Left column-Specimen \#1: $b$-value (a) per 100 events, (b) for all events per load step, (c) for all peaks per load step. Right column-Specimen \#2: (d-f) description as per (a-c). 
Fig. $12 \mathrm{~b}$ plots the $b$-value considering all the events per load step (one $b$-value per load step). The plot shows similar trends as in Fig. 12a, with the difference that the major events A1, B1 and C1 are better marked, with the $b$-value reaching a minimum. That means that these brittle local failure events are accompanied by a considerable increase of the number of the high-amplitude events in relation to the low-amplitude events. Between B1 and C1 the $b$-value increases again, although there is a significant number of high-amplitude events as shown in Fig 9d-top. This is because after the A1/B1 transition, the high $A E$ activity stage is characterised by an increase in the number of both low-amplitude and high-amplitude events.

Fig. 12c plots the $b$-value based on the distribution of all peaks per load step (one $b$-value per load step). The main trends are similar to Fig. 12b, marking again clearly when severe damages that are critical for the change in the structural behaviour of the specimen are taking place. Note that this approach is based on the signal peaks retrieved from the featured-based mode of the in-house DAQ system, without the need to use an event detection post-processing algorithm on continuous waveform data.

\subsubsection{Specimen \#2}

Fig. $12 \mathrm{~d}$ is the corresponding Fig. 12 a for specimen $\# 2$ and presents the evolution of the $b$-value per 100 events. The $b$-value clearly marks the $\mathrm{A} 2$ transition from the low AE activity stage to the high $\mathrm{AE}$ activity stage. With this approach, there is no significant change in $b$-value for the intermediate $\mathrm{B} 2, \mathrm{C} 2$ and $E 2$ events of the high AE activity stage. Fig. 12d shows that $A E$ sensors closer to active regions, such as AE1, give lower $b$-values compared to sensors away from active regions, such as AE4.

Figs. $12 \mathrm{e}$ and $12 \mathrm{f}$ are the corresponding Figs. $12 \mathrm{~b}$ and $12 \mathrm{c}$ for specimen $\# 2$ and present the $b$-value based on the number of events and peaks, respectively. Both approaches mark all the severe events. A slight difference appears in the event D2, which is highlighted more in the analysis based on events. Note that the D2 was not a brittle failure event and appears less severe in the analysis based on the number of peaks. As in Fig. 12d, Figs. 12e and 12f show that sensors in more active areas offer lower $b$-values.

The $b$-value trends presented in Fig. 12 for both specimens are comparable to results reported in literature for physical testing of brittle materials [28]. For concrete beams, a $b$-value close to or below 1 has been associated with macro-cracking formation, while larger values have been associated with micro-cracking dominance [25]. Multiple $b$-value drops during concrete beam bending tests under gradually increasing loading have been reported in [29] and have been associated with unstable crack growth.

\section{Discussion and future work}

Combined deformation and cracking monitoring may enhance the ability of engineers to develop realtime structural alert systems and assess the structural performance of ageing infrastructure.

At an early damage state, opening of cracks in tensile zones due to bending is a gradual phenomenon. AE sensors are able to detect micro-cracking activity (which corresponds to cycles 0 to 4000 for both specimens) before the initiation of visible cracks, with the condition that the AE sensors are located near the area of interest. Displacement or strain sensors, such as LVDTs or fibre optics can easily capture this gradual phenomenon. However, as deterioration progresses, damage modes such as mortar or brick crushing, joint sliding or diagonal shear are brittle failures which may not be accompanied by a pre-event increase of the deformation rate. This study shows that in most cases there is a clear pre-event increase of the cracking rate which can be monitored with the aid of simple 
feature-based $A E$ algorithms. This type of analysis is computationally cheap and can be easily implemented using real-time data for long-term monitoring applications. As a result, AE monitoring, enhanced with displacement or strain information, can serve as a method for the development of realtime structural alert systems for ageing infrastructure, spanning all potential structural performance levels that the structure might experience throughout its life, from low damage state to near collapse state.

Furthermore, severity assessment analysis based on an AE amplitude distribution parameter, such as the $b$-value, combined with common featured-based analysis, may contribute to identifying different structural performance states. For instance, this paper shows that the low damage stage with dominant micro-cracking behaviour has low AE activity and a high $b$-value. The high damage stage that is associated with extensive micro- and macro-cracking has both high AE activity and $b$-value. The transition stage, where macro-cracking events temporarily become more dominant in relation to micro-cracking events, is characterised by medium or high AE activity and a low $b$-value. These findings are summarised in Table 1, which presents an indicative example of structural performance assessment based on AE results.

Table 1. Indicative example of a high-level structural performance characterisation

\begin{tabular}{llll}
\hline $\begin{array}{l}\text { Structural } \\
\text { performance } \\
\text { state }\end{array}$ & $\begin{array}{l}\text { Low Damage / } \\
\text { Micro-cracking }\end{array}$ & $\begin{array}{l}\text { Transition / } \\
\text { Macro-cracking }\end{array}$ & $\begin{array}{l}\text { High Damage / } \\
\text { Extensive Micro- } \\
\text { and Macro-cracking }\end{array}$ \\
\hline $\begin{array}{l}\text { AE activity } \\
\text { (counts, energy } \\
\text { and amplitude) }\end{array}$ & Low & Medium/High & High \\
\hline$b$-value & High & Low & High \\
\hline
\end{tabular}

The current work explores the possibility to use routine feature-based analysis combined with economic and versatile infrastructure monitoring systems, which are easily expandable to support multi-sensing remote monitoring, in order to better understand the overall structural performance of masonry under cyclic loading and gradual deterioration. This work aims to leverage rapid asset management tools for ageing infrastructure networks. Damage localisation and source discrimination algorithms for masonry (see for instance Livitsanos et al. [30]), and advanced statistics, have an important role to play for asset management. This is part of ongoing and future research. Exploring the benefits of multi-sensing information is also appealing for future current research. Apart from the benefit of combining AE with deformation monitoring (e.g. fibre optic sensing) discussed previously, the combined use of transducers of varying frequency ranges, for instance the use of high-sensitivity accelerometers to capture lower frequency vibrations together with AE sensors, may contribute to the structural performance assessment and indication of impending failure, as was shown by Schiavi et al. [31]. Finally, extension of this experimental investigation to study the AE behaviour of masonry with different mechanical characteristics, environmental effects, and the effect of high-cycle fatigue loading, is also of interest for future research.

\section{Conclusions}

This paper studies the AE behaviour of two masonry specimens under progressive damage due to a biaxial stress state and cyclic loading. The specimens experienced a combination of compression, shear and bending, similar to what arch bridge sections experience during train loading. An in-house 
AE sensing system was developed for this study, which can operate in both feature-based and waveform-based modes.

Feature-based $A E$ analysis shows that the two specimens experienced two main damage stages. In the first stage there was a gradual propagation of joint bond failures due to bending. AE sensors were able to capture micro-cracking activity before cracks became visible. This stage was characterised by a relatively low AE energy release. The second stage was characterised by high AE activity with the generation of a considerably larger number of micro- and macro-cracking events. For both specimens, the transition into this second, high-damage stage happened after brittle local failures due to the combined action of shear and compression. Feature-based AE analysis captured a pre-event increase of cracking rate before brittle local failure occurred, which was not necessarily accompanied by an increase in the deformation rate. This indicates that combining displacement or strain monitoring with AE monitoring could enable the development of early warning structural alert systems covering a wide range of damage modes.

When local brittle failure occurs, the number of high amplitude AE signals temporarily dominate over the number of low amplitude signals. The paper compares three different approaches of the $b$-value statistical method to describe this behaviour, by performing an analysis (i) for every $n$ number of $A E$ events (classic approach), (ii) for all events per load step and (iii) for all peaks per load step. The three approaches present comparable results. Approaches (ii) and (iii), proposed in this study, showed more consistency in detecting the major brittle events that occurred during the tests. Furthermore, the third approach (iii) is based on signal features (peaks) directly retrieved from the DAQ's feature-based mode, reducing the computational cost and facilitating real-time processing.

To this end, the paper presents an example of how these findings can be used for identifying different structural performance stages of ageing infrastructure.

\section{Acknowledgements}

This work is being funded by the Lloyd's Register Foundation, EPSRC and Innovate UK through the Data-Centric Engineering programme of the Alan Turing Institute and through the Cambridge Centre for Smart Infrastructure and Construction. Funding for laboratory tests and the field monitoring installation was also provided by the EPSRC (grant Ref. EP/N021614/1) and by Innovate UK (grant Ref. 920035). The research data supporting this publication can be accessed at https://doi.org/10.17863/CAM.54277. Network Rail has supported this research by providing power, technical support and site access for the Marsh Lane Bridge monitoring.

\section{References}

[1] Ye C, Acikgoz S, Pendrigh S, Riley E, DeJong MJ. Mapping deformations and inferring movements of masonry arch bridges using point cloud data. Eng Struct 2018; 173(15): 530-545. DOI: 10.1016/j.engstruct.2018.06.094

[2] Orbán Z, Gutermann M. Assessment of masonry arch railway bridges using non-destructive insitu testing methods. Eng Struct 2009; 31(10): 2287-2298. DOI: 10.1016/j.engstruct.2009.04.008

[3] Acikgoz S, DeJong MJ, Soga K. Sensing dynamic displacements in masonry rail bridges using 2D digital image correlation. Struct Control Health Monit 2018; 25(8): e2187. DOI: 10.1002/stc.2187

[4] Alexakis H, Franza A, Acikgoz S, DeJong MJ. A multi-sensing monitoring system to study deterioration of a railway bridge. In: Chen G, Alampalli S, editors. Proceedings of the 9 th 
International Conference on Structural Health Monitoring of Intelligent Infrastructure (SHMII-9), St. Louis, Missouri; 2019, p. 1171-1176. DOI: 10.17863/CAM.38633

[5] Alexakis H, Franza A, Acikgoz S, DeJong MJ. Structural Health Monitoring of a masonry viaduct with Fibre Bragg Grating sensors. In: Proceedings of the International Association for Bridge and Structural Engineering (IABSE) Symposium, Towards a Resilient Built Environment Risk and Asset Management, Guimarães; 2019, p. 1560-1567. DOI: 10.17863/CAM.38693

[6] Alexakis H, Franza A, Acikgoz S, DeJong MJ. Monitoring bridge degradation using dynamic strain, acoustic emission and environmental data. In: DeJong MJ, Schooling JM, GMB Viggiani, editors. International Conference on Smart Infrastructure and Construction (ICSIC): Driving data-informed decision-making. ICE Publishing; 2019, p. 523-532. DOI: 10.1680/icsic.64669.523

[7] Miller RK, McIntire P. Nondestructive Testing Handbook: Acoustic Emission Testing. American Society for Non-destructive Testing; 1987.

[8] Gautschi G. Acoustic Emission Sensors. In: Piezoelectric Sensorics. Springer, Berlin, Heidelberg; 2002, p. 199-207. DOI: 10.1007/978-3-662-04732-3_10

[9] Mostafapour A, Davoudi S. Analysis of leakage in high pressure pipe using acoustic emission method. Appl Acoust 2013; 74(3): 335-342. DOI: 10.1016/j.apacoust.2012.07.012

[10] Behnia A, Chai HK, Shiotani T. Advanced structural health monitoring of concrete structures with the aid of acoustic emission. Constr Build Mater 2014; 65: 282-302. DOI:

10.1016/j.conbuildmat.2014.04.103

[11] Eberhardt E , Stead D, Stimpson B. Quantifying progressive pre-peak brittle fracture damage in rock during uniaxial compression. Int J Rock Mech Min 1999; 36(3): 361-380. DOI: 10.1016/S01489062(99)00019-4

[12] Smith A, Dixon N. Acoustic emission behaviour of dense sands. Géotechnique 2019. DOI: 10.1680/jgeot.18.P.209

[13] Shigeishi M, Colombo S, Broughton KJ, Rutledge H, Batchelor AJ, Forde MC. Acoustic emission to assess and monitor the integrity of bridges. Constr Build Mater 2001; 15(1): 35-49. DOI: 10.1016/S0950-0618(00)00068-4

[14] Tomor AK, Melbourne C. Monitoring masonry arch bridge response to traffic loading using acoustic emission techniques. In: Proceedings of the 5th international conference on arch bridges, Madeira, Portugal; 2007, p. 281-288.

[15] De Santis S, Tomor AK. Laboratory and field studies on the use of acoustic emission for masonry bridges. NDT \& E International 2013; 55: 64-74. DOI: 10.1016/j.ndteint.2013.01.006

[16] Carpinteri A, Lacidogna G, Manuello A, Binda L. Monitoring the structures of the ancient temple of Athena incorporated into the Cathedral of Syracuse. In: Masia M, Totoev Y, Page A, Sugo H editors. Proceedings of the 14th International Brick and Block Masonry Conference, Sydney, Australia; 2008.

[17] Verstrynge E, Schueremans L, Van Gemert D, Wevers M. Monitoring and predicting masonry's creep failure with the acoustic emission technique. NDT \& E International 2009; 42(6): 518-523. DOI: 10.1016/j.ndteint.2009.03.001

[18] Masera D, Bocca P, Grazzini A. Frequency Analysis of Acoustic Emission Signal to Monitor Damage Evolution in Masonry Structures. J Phys: Conf Ser 2011; 305: 012134. DOI: 10.1088/17426596/305/1/012134 
[19] Tomor AK, Verstrynge E. A joint fatigue-creep deterioration model for masonry with acoustic emission based damage assessment. Constr Build Mater 2013; 43: 575-588. DOI:

10.1016/j.conbuildmat.2013.02.045

[20] Melbourne C, Tomor AK. Application of acoustic emission for masonry arch bridges. Strain 2006; 42: $165-172$.

[21] Acikgoz S, DeJong MJ, Kechavarzi C, Soga K. Dynamic response of a damaged masonry rail viaduct: Measurement and interpretation. Eng Struct 2018; 168: 544-558. DOI: 10.1016/j.engstruct.2018.04.054

[22] Shiotani T, Shigeishi M, Ohtsu M. Acoustic emission characteristics of concrete-piles. Constr Build Mat 1999; 13(1-2): 73-85. DOI: 10.1016/S0950-0618(99)00010-0

[23] Shiotani T, Bisschop J, Van Mier JGM. Temporal and spatial development of drying shrinkage cracking in cement-based materials. Eng Fract Mech 2003; 70(12): 1509-1525. DOI: 10.1016/S00137944(02)00150-9

[24] Shiotani T, Ohtsu M, Ikeda K. Detection and evaluation of AE waves due to rock deformation. Constr Build Mat 2001; 15(5-6): 235-246. DOI: 10.1016/S0950-0618(00)00073-8

[25] Colombo IS, Main IG, Forde MC. Assessing Damage of Reinforced Concrete Beam Using " $b$ value" Analysis of Acoustic Emission Signals. J Mater Civ Eng 2003; 15(3): 280-286. DOI: doi.org/10.1061/(ASCE)0899-1561(2003)15:3(280)

[26] Gutenberg B, Richter CF. Seismicity of the earth and associated phenomena. In: Frequency and energy of earthquakes. Princeton, NJ: Princeton University Press; 1949, p. 17-19.

[27] Farhidzadeh A, Salamone S, Luna B, Whittaker A. Acoustic emission monitoring of a reinforced concrete shear wall by b-value-based outlier analysis. Struct Health Monit 2012; 12(1): 3-13. DOI: $10.1177 / 1475921712461162$

[28] Sammonds PR, Meredith PG, Murrel SAF, Main IG. Modelling the damage evolution in rock containing pore fluid by acoustic emission. Rock Mechanics in Petroleum Engineering, 29-31 August, Delft, Netherlands; 1994.

[29] Vidya Sagar R. Importance of acoustic emission based $b$-value in the study of fracture process in reinforced concrete structures. Proceedings of the 9 th International Conference on Fracture Mechanics of Concrete and Concrete Structures, Berkeley, USA; 2016. DOI: 10.21012/FC9.040

[30] Livitsanos G, Shetty N, Hündgen D, Verstrynge E, Wevers M, Van Hemelrijck D, Aggelis DG. Acoustic emission characteristics of fracture modes in masonry materials. Constr Build Mater 2018; 162: 914-922. DOI: 10.1016/j.conbuildmat.2018.01.066

[31] Schiavi A, Niccolini G, Tarizzo P, Lacidogna G, Manuello A, Carpinteri A. Analysis of acoustic emissions at low frequencies in brittle materials under compression. Proceedings of the Annual Conference \& Exposition on Experimental and Applied Mechanics (SEM), Albuquerque, New Mexico; 2009. Paper No. 539, pp. 16-23. 